\title{
Manufacturing of a High-Temperature Resistojet Heat Exchanger by Selective Laser Melting
}

\author{
F. Romei ${ }^{\text {a*}}$, A. N. Grubišićb ${ }^{\text {D. Gibbon }}{ }^{\mathrm{c}}$ \\ a University of Southampton, Faculty of Engineering and the Environment, SO17 1BJ, UK, f.romei@soton.ac.uk \\ ${ }^{\mathrm{b}}$ University of Southampton, Faculty of Engineering and the Environment, SO17 1BJ, UK, a.grubisic@soton.ac.uk \\ c Surrey Satellite Technology Ltd, Guildford, GU2 7YE, UK, d.gibbon@,sstl.co.uk \\ * Corresponding Author
}

\begin{abstract}
The paper presents the design, manufacturing and postproduction analysis of a novel high-temperature spacecraft resistojet heat exchanger manufactured through selective laser melting to validate the manufacturing approach. The work includes the analysis of critical features of a heat exchanger with integrated converging-diverging nozzle as a single piece element. The metrology of the component is investigated using optical analysis and profilometry to verify the integrity of components. A novel process of high-resolution micro-Computed Tomography (CT) is applied as a tool for volumetric non-destructive inspection and conformity since the complex geometry of the thruster does not allow internal examination. The CT volume data is utilised to determine a surface mesh on which a novel perform coordinate measurement technique is applied for nominal/actual comparison and wall thickness analysis. A thin-wall concentric tubular heat exchanger design is determined to meet dimensional accuracy requirements through nominal/actual comparison analysis. The work indicates the production of fine structures with feature sizes below 200 $\mu \mathrm{m}$ in $316 \mathrm{~L}$ stainless via selective laser melting is feasible and opens up new possibilities for the future developments in multiple industries.
\end{abstract}

Keywords: Resistojet, All-electric Spacecraft, Selective Laser Melting, 316L Stainless Steel, Computed Tomography, Non-Destructive Inspection.

\section{Acronyms/Abbreviations}

Additive Manufacturing (AM), Computed Tomography (CT), Electric Discharge Machining (EDM), Electric Propulsion (EP), High-Temperature Resistojet (HTR), Specific Impulse (ISP), Maximum Operating Temperature (MOT), Reaction Control Thrusters (RCS), Scanning Electron Microscope (SEM), Selective Laser Melting (SLM), Additively Manufactured Resistojet (AMR).

\section{Introduction and Background}

Spacecraft electrothermal propulsion systems increase the enthalpy of a propellant through the addition of electrical power. Enthalpy is energetically traded for kinetic power of the propellant as it is expanded and accelerated through a nozzle to produce thrust. Resistojet thrusters work on this principle by electrically heating the propellant via a resistance element. The propellant exit velocity, $u_{e}$, of this thruster increases proportionally to the square root of the product of stagnation gas temperature $T_{0}$ and the constant pressure specific heat of the propellant gas, $c_{p}$. Eq.(1) gives the specific impulse (ISP), which is a measure of the fuel efficiency of rocket engines expressed in seconds, where $g_{0}$ $=9.806 \mathrm{~ms}^{-1}$ is the sea-level gravitational acceleration and $\eta_{n}$ is the nozzle efficiency. The nozzle efficiency for monoatomic gases accounts for incomplete expansion, viscous flow and radial flow losses, and can be assumed $<95 \%$ [1]. Conventional resistojets using xenon propellant operate at a temperature $<1,000 \mathrm{~K}$, whereas for xenon $c_{p}=158$ $\mathrm{Jkg}^{-1} \mathrm{~K}^{-1}$, with a resulting ISP is in the region of $50 \mathrm{~s}$.

ISP $=\mathrm{u}_{\mathrm{e}} / \mathrm{g}_{0} \approx \eta_{\mathrm{n}} \sqrt{2 \mathrm{c}_{\mathrm{p}} \mathrm{T}_{0}} / \mathrm{g}_{0}$

On SSTL spacecraft platforms using xenon propulsion, a 30-Watt resistojet thruster improves ISP over cold gas systems from $30 \mathrm{~s}$ to $48 \mathrm{~s}[2,3]$; a $60 \%$ increase in propellant efficiency for a few thousand GBP. The primary driver of high performance resistojet technology is now the all-electric GEO telecommunication bus [4, 5]. All-electric spacecraft will carry Hall Effect Thruster (HET) or Gridded Ion Engines (GIE) for orbit raising and north-south station keeping, however additional reaction control system (RCS) thrusters are required for lower impulse requirements such as attitude, momentum control and possibly east-west station keeping functions usually requiring an additional hydrazine system at significant additional complexity and cost. A more idyllic solution is a resistojet, which can operate from a common xenon propellant system in parallels with the HET or GIE to fulfil the RCS role. A requirements gathering exercise for the RCS resistojet was conducted as part of a UK National Space Technology Programme funded 
study, in which many prime contractors were retuned a request for information regarding detailed performance targets and qualification requirements for all-electric platforms. In this exercise it was determined that the majority of prime contractors favoured an ISP target of $100 \mathrm{~s}$ for a xenon resistojet with a power requirement of less than $150 \mathrm{~W}$, target thrust level of $50-500 \mathrm{mN}$ and total impulse for $7.5 \mathrm{kNs}$ for all-electric spacecraft. For all-electric spacecraft the PPU requirements for a $150 \mathrm{~W}$ power supply are considered negligible compared to the savings in system mass and cost by elimination of second hydrazine system and the fact that the PPU will already contain power supplies which are very likely to be shared with the electric propulsion system, for example a cathode heater supply.

The high performance resistojet also has relevance to existing small spacecraft busses. The information gathering exercise determined that for LEO spacecraft primes favoured a target ISP of greater than $80 \mathrm{~s}$ for a xenon resistojet with a power requirement of less than $50 \mathrm{~W}$, target thrust level of $20-50 \mathrm{mN}$ and total impulse of $10 \mathrm{kNs}$. An example of the potential saving can be shown on the SSTL-300 platform, which has $300 \mathrm{~kg}$ of total mass, $150 \mathrm{~kg}$ of payload mass, $10 \mathrm{~kg}$ xenon load and uses the existing T-50 resistojet (Fig. 1). The SSTL-300 delta-V with the current T-50 resistojet (48 s ISP) is given by Eq.(2), where $m_{0}$ and $m_{f}=m_{0}-m_{p}$ are the initial and final mass of the spacecraft respectively, with propellant mass $m_{p}$. If a high-temperature resistojet with $80 \mathrm{~s}$ was available, it could be used to either reduce the propellant loading from $10 \mathrm{~kg}$ to $6 \mathrm{~kg}$ for the same $16 \mathrm{~ms}^{-1}$ delta-V, Eq.(3), or give the platform a $26.6 \mathrm{~ms}^{-1}$ delta-V, Eq.(4), representing a $67 \%$ increase for the same fuel loading, where prime quantities refer to the high-temperature resistojet. At a current xenon cost of $£ 2,000 / \mathrm{kg}$, this represents a saving of $£ 8,000$ with much greater savings in launch costs. For LEO spacecraft, the intention is to operate the thruster directly from a bus $28 \mathrm{~V}$ voltage, therefore no additional PPU would be necessary.

$$
\begin{aligned}
& \Delta \mathrm{v}=\mathrm{g}_{0} \mathrm{I}_{\mathrm{sp}} \ln \left(\mathrm{m}_{0} / \mathrm{m}_{\mathrm{f}}\right)=16 \mathrm{~ms}^{-1} \\
& \mathrm{~m}_{\mathrm{p}}^{\prime}=\mathrm{m}_{0}\left\{1-\exp \left[-\Delta \mathrm{v} /\left(\mathrm{g}_{0} \mathrm{I}_{\mathrm{sp}}^{\prime}\right)\right]\right\}=6 \mathrm{~kg} \\
& \Delta \mathrm{v}^{\prime}=\Delta \mathrm{v} \times \mathrm{I}_{\mathrm{sp}}^{\prime} / \mathrm{I}_{\mathrm{sp}}=26.6 \mathrm{~ms}^{-1}
\end{aligned}
$$

Many of the gains in the UK space sector have been driven by innovation in niche markets such as the innovative and highly successful "affordable satellite" concept. Robust resistojet propulsion systems are integral to SSTL satellite capabilities enabling numerous commercial missions. These include the successful first generation Disaster Monitoring Constellation satellites (ALSAT-1, BilSAT, NigeriaSAT-1, UK-DMC), second DMC generation (Beijing-1, UK-DMC 2, Demios-1, NigeriaSAT-2), the five satellite Rapid Eye constellation, the European Galileo Testbed (GSTB) GIOVE validation satellite [6], essential in securing European GPS, and numerous other satellites.

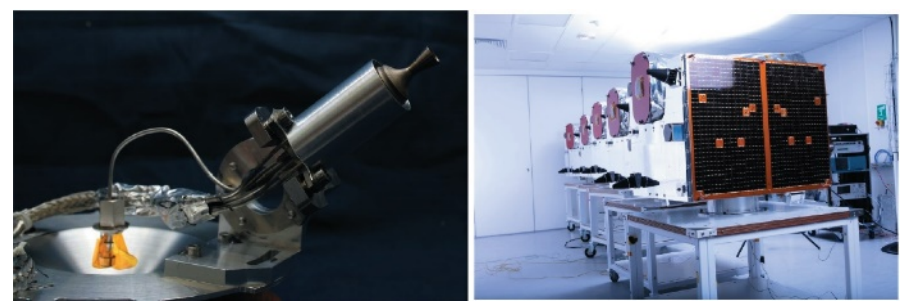

Fig. 1. SSTL's T-50 resistojet (left) and Rapid Eye Constellation Satellites 1-5 (right)

The new performance demands for a high-temperature resistojets elevate the hot gas temperature requirement to a minimum of $2,400 \mathrm{~K}$ for $80 \mathrm{~s}$ ISP or $3,300 \mathrm{~K}$ for $95 \mathrm{~s} \mathrm{ISP}$, representing significant materials and design challenges. Beyond the flow kinetics, a major practical challenge facing the high-temperature resistojet technology is retaining structural integrity at the very high temperatures demanded, whilst minimizing viscous and radiative heat losses. The University of Southampton has identified a technical solution to this problem and advanced thermo-fluidic multiphysics simulations are currently ongoing as part of a current collaboration with Surrey Satellite Technology Limited (SSTL), as well as the iterative design development in order to achieve the necessary performance. The current challenge is to finalise a design and conduct the necessary high temperature materials and process validation to ensure any critical technologies or processes are technically feasible followed by construction and performance testing of a development model thruster. 


\subsection{Past High-Temperature Resistojet Designs}

Since 1960, various high temperature resistojet concepts have been developed in Russia. Two high temperature concepts use indirect propellant heating and direct propellant heating respectively. The first one, developed by Fakel Enterprise, uses an inner graphite element, which radiatively heats the incoming propellant and the outer concentric channels walls through which the propellant flows. With a power range of $80-600 \mathrm{~W}$, and ammonia propellant, the maximum gas temperature was $2,500 \mathrm{~K}$ developing $250 \mathrm{~s}$ ISP. Today, Russian satellites are equipped with engines of the type EHT-15 developed by NIIEM-ELKOS, where the heating element in this case is a porous medium and is located in the inner heating chamber. The propellant is ammonia with a power range of 100-450 W [7].

The Marquardt Corporation (US) made extensive work in high-temperature resistojets and developed both the 3$k w$ Concentric Tubular Resistojet [8] (1966) and the Ten-Millipound Resistojet [9] (1968). The first consisted of a recirculating flow heat exchanger also acting as heater, constructed of tubular elements made of tungsten, which has the highest melting point among all refractory metals. With the Ten-Millipound Resistojet, the same heat exchanger concept was used with the substantial change of replacing tungsten with pure rhenium. The main reason for this choice was that this material is readily welded to produce strong joints. This thruster was designed for either hydrogen or ammonia propellants, reaching a stagnation temperature of 2,420 K. The Rocket Propulsion Establishment, RPE, (Westcott, England), developed the $J 3$ resistojet in the 1970s. This $3 \mathrm{~kW}$ thruster was successfully tested at the Oxford University in 1973, obtaining an overall efficiency of $68.1 \%$ with a stagnation temperature of 2,480 K and $824 \mathrm{~s}$ ISP with hydrogen. Similarly to the Marquardt Corporation resistojets, its design consists of a concentric tubular heat exchanger terminating in a conical nozzle, both manufactured from rhenium. Sherwood describes the fabrication and assembly procedure of this thruster in [10]. Thin-wall rhenium cylinders were constructed by Chemical Vapour Deposition (CVD). The concentric tubular geometry was obtained by EB welding of small strut connectors to ensure both electrical continuity of the heater and recirculation of the propellant.

\subsection{The Selective Laser Melting Manufacturing Process}

Additive Manufacturing (AM) is applicable to a wide range of materials, including metals. It enables production of parts on-demand starting from a 3D model data and, at the same time, it guarantees production cost, energy investment and if production processes and process steps are simplified, it also potentially allows for reductions in carbon footprint. The international community is working on several aspects toward the standardisation and improvement of metal AM: machine-to-machine variability, physics-based models for microstructure, properties and performance, in-situ process monitoring techniques, standardisation of the 3D model data file format [11].

The three main metal AM methods categorised by material feed stock are: (a) powder bed system, (b) powder feed system and (c) wire feed systems. In the first case, the powder bed is created by raking powder across the work area (Fig. 2). The energy source (laser or electron beam) then delivers energy to the surface of the bed sintering or melting the powder into the desired layer shape. The process is repeated to create a three dimensional shape. In the powder feed system, the powder is carried through a nozzle to the surface where a laser is used to melt it locally. The main advantage of this system is the ability to build larger volumes and to refurbish worn or damaged components. Finally, the feed stock method consists of a wire, which is fused by the energy source (electron beam, laser beam or plasma arc). The advantage of this method is the high deposition rate for large volumes, however requiring more extensive post-manufacturing machining.

Compared with the powder feed and the wire feed systems, only the powder bed system permits manufacture of small components and high-resolution features (up to $100 \mu \mathrm{m}$,) maintaining dimensional control. Within the powder bed systems, a metal printer uses one of the following processes: Electron Beam Melting (EBM), Selective Laser Melting (SLM) or Direct Metal Laser Sintering (DMLS). Both EBM and SLM fully melt the powder layer into a homogeneous part using an electron beam or a laser source respectively. DMLS does not heat the powder to its melting point, but fuses the powder at a molecular level. The latter process is also used for plastic, glass and ceramic materials.

SLM machines are composed of three main units: (1) laser and scanner system (2) controller system and (3) build chamber. Fig. 3 shows a schematic of primary parameters involved into the SLM process: laser power, focus diameter, scan speed, hatching distance and layer thickness. SLM is performed within an inert/protective controlled atmosphere using mostly $\mathrm{N}_{2}$ or Ar gas circulation.

Among the metal additive manufacturing technologies, the most suitable for HTR fabrication is the powder bed system. SLM can produce very high-density parts, reaching above $99 \%$ of the bulk material density. However, for some applications, the remaining porosity may be an issue. Yasa and Kruth [12] illustrate how re-melting of each layer during the manufacturing process can almost eliminate porosity, reaching values up to $99.968 \%$ for AISI $316 \mathrm{~L}$, depending on the re-melting strategy adopted. The same concept is used to improve the specimen surface quality, lowering the initial surface roughness by $90 \%$ with the possibility of reducing the staircase-effect between layers. 
SLM has been selected as a candidate technology for HTR as it allows for high-resolution features, complex and net-shaped parts and to maintain dimensional control over the component. It is important to be aware of the properties of SLM produced parts and of the constraints that may arise.

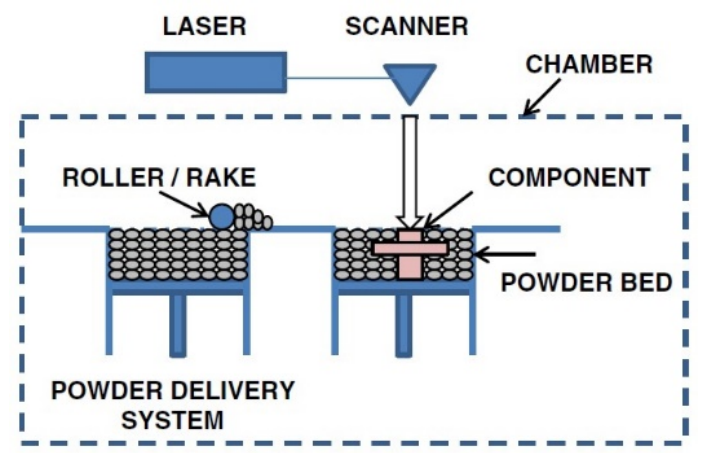

Fig. 2. Generic illustration of an AM laser powder bed system [11].

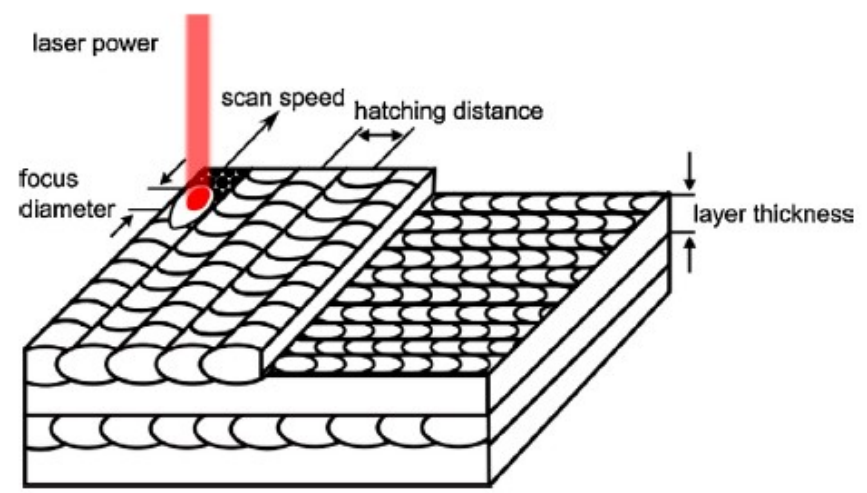

Fig. 3. Relevant process parameter for selective laser melting [13].

\subsubsection{Common Manufacturing Defects}

The primary defects resulting from the SLM process are porosity, balling, residual stress and cracks. In addition, surface roughness and geometric accuracy are essential parameters for the component quality evaluation. Postprocessing can be used to improve the component quality by relaxing residual stress with specific heat treatment, whilst improving the surface finish when required.

During the SLM process external pressure is not applied, therefore porosity is associated with capillarity forces, gravity and temperature gradient. The resulting pores can be large and irregular due to the lack of complete melting, lack of powder feeding within small depressions, and spherical pores generated by trapped gas. However, by optimising the laser processing parameters, the material density can be greater than 99\%. For Ti6Al4V (the most studied SLM materials at present) density is above $99.9 \%$. Using the SLM process parameters it is also possible to manufacture structures with a predefined porosity. Abele et al. [13] investigate on 17-4 PH stainless steel and found correlations of SLM manufacturing parameters that allows for controlling of the porosity of stainless steel thin-wall structures, such hatching distance, scan speed and laser power. Scan speed is found to have the greatest influence on the surface roughness, including for AlSi10Mg aluminium alloy [14]. Different post-processing techniques to improve the surface finish on $316 \mathrm{~L}$ samples have also been investigated in showing that combined mechanical and electro abrasion methods result in a better final surface finish than for a single method. [15].

Balling is a process that occurs as the molten material fails to wet the underlying substrate due to surface tension. Balling results in irregular scan tracks with the effect of increasing the surface roughness and porosity. This process depends on wettability, which in turn depends on material properties and processing variables. Avoiding oxidation and contamination during printing limits this phenomenon. Balling is found most significant for both low and high laser energy densities, while surface roughness is found to increase with the laser point distance (the distance between successive laser hits) and the exposure time (the time the laser remains on a particular point) [16]. 
All laser-based processes, including SLM, introduce a large amount of residual stress due to the highly directional thermal gradients. After removing the printed component from the build plate, the residual stress is partially relieved, resulting in component deformation. Generally, tensile stress accumulates on the top and the bottom of the component, while compressive stress locates in the centre part. Excessive thermal stress can cause cracking of the component. In general, alloys are prone to hot cracking and solidification cracking and are not prevalent in SLM materials. In addition, SLM suffers from low-quality of down-facing surfaces with greater upper-surface roughness. As an example, in microstructures with open porosity made by Ti6A14V for biomedical scaffolds, numerous powder grains are heterogeneously attached on the SLM as-printed surface and can be released, harming the living body. These nonmelted powder grains attached to the strut surface are successfully removed by chemical etching [17].

\subsection{Current High Temperature Resistojet Design}

The aim of the research is to enable the design, development and operation of a High-Temperature Resistojet (HTR) prototype through a combination of design, computer modelling [18], manufacturing verification and validation through post manufacturing analysis and performance testing. Fundamentally, the driver of performance is the operating temperature of the thruster, since this drives the operating gas temperature and thus the attainable ISP of the device. Currently, resistojets are incapable of such performance due to materials limitations and difficulty in high temperature design. The HTR is defined here as a resistojet thruster capable of raising the stagnation temperature of the propellant in the region of 3,000 K. The HTR concept has a total thruster efficiency similar to other resistojet applications, in the range of $65-90 \%$. The temperature definition of 3,000 $\mathrm{K}$ is close to the temperature limit of the highest-melting-point refractory metals and their alloys including molybdenum, tantalum, tungsten and rhenium.

\subsubsection{Heat Exchanger Concept}

From the literature shown in section 1.1, high-temperature resistojets have best performance when using a recirculating flow geometry composed by concentric tubular element on which an electric potential is applied to exert Joule heating. Refractory metals have been used to reach gas temperatures above 2,400 K with success. However, the manufacturing process was costly and challenging involving EB welding of small connectors to develop a concentric tubular geometry. Although the concentric tubular heat exchanger assembly is complex, an investigation was made on using metal Additive Manufacturing (AM), and in particular Selective Laser Melting (SLM), to build a recirculating flow heat exchanger as a single component. AM is proposed as a process that could substantially reduce assembly complexity and cost while allowing greater freedom of design. Fig. 4 shows the HTR heat exchanger design for SLM production. The xenon propellant (shown in purple) flows from the outer annular channel, and then recirculates a number of times until being expanded through the nozzle to produce thrust. By applying an electric potential to its terminals, the heat exchanger increases the gas stagnation temperature along the flow path. In the HTR design the propellant is directly heated, because the heat exchanger and the heater coincide. In addition, the nozzle is integrated with the heat exchanger to form a single component.

In order to achieve the required current-voltage characteristics for the heater, thin tubular walls with thickness on the order of $100 \mu \mathrm{m}$ are required. A thinner and smaller-diameter wall produces greater resistive dissipation. Being able to use a wide range of wall thicknesses allows a better optimization of heat transfer across the propellant flow path. It should be noted that the resistivity of refractory metals is comparable to the resistivity of $316 \mathrm{~L}$ stainless steel at the respective maximum operating temperatures of those materials, therefore there is design similarity in terms of resistivity for both materials under their respective operating conditions. This implies that there will not be a significant difference in heat exchanger wall thickness requirements when moving from $316 \mathrm{~L}$ stainless to refractory materials in order to deliver a comparable dissipation power with very similar current-voltage characteristics at temperature. Since the production of refractory components with wall thickness on the order of 100 microns is already commercially available, there is no indication that the transition to refractory metal SLM is not achievable. 


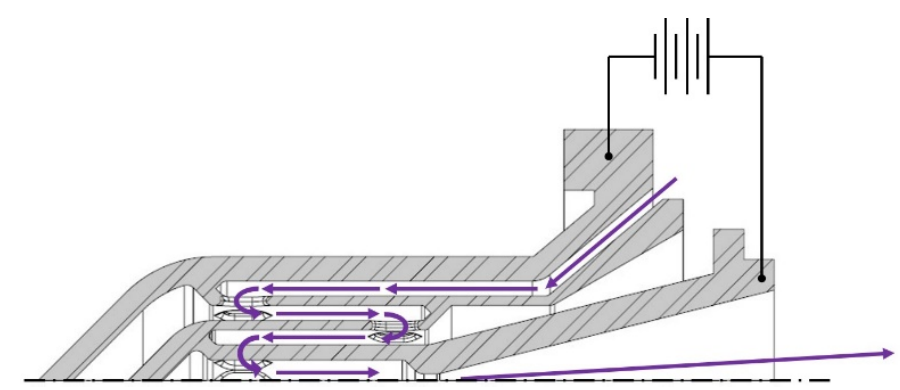

Fig. 4. Axial-symmetric section view of the HTR heat exchanger concept. The xenon flow path (purple) and the electrical interface are shown.

\section{Research Methodology}

The HTR concept, described in section 1.3.1, consists of a thin-wall concentric tubular heat exchanger with integrated nozzle. The concept has been designed for the first time as a single piece for SLM production and therefore requires a material and manufacturing verification exercise to determine whether SLM can enable such complex design. In addition, it is necessary to determine how the intrinsic limitations of this technology, described in 1.2.1, affect the HTR production. In order to make this investigation it is necessary to select a suitable material, which will constitute the basis for a subsequent extension of this proof of concept study to refractory metals. Specimens for the current study are produced in stainless steel, grade 316L, and are analysed with optical inspection tools when possible, while non-destructive inspection is used to analyse the full HTR heat exchanger component. NASA [16] used a similar process for NDI on DMLS manufactured subscale rocket injectors. The main objectives of the manufacturing verification are to characterise the surface morphology and roughness of the 316L SLM components and to use nondestructive inspection of the HTR heat exchanger to determine dimension accuracy with respect to the CAD design. This paper provides the analysis of a first iteration of the HTR heat exchanger design. Further iterations will eventually lead to a functional prototype. It should be emphasised that this preliminary feasibility study is being conducted $316 \mathrm{~L}$ stainless steel, as a precursor to refractory metal SLM. While it is appreciated that refractory materials may delivery a differing quality of component, since refractory SLM is still in its infancy, this research is aimed at developing the basis of manufacturing verification for such a component, as well as providing eventual validation data for multiphysics models of the full thruster.

\subsection{Material selection}

Table 1 shows the Maximum Operating Temperature (MOT) of the available metal powder for powder bed systems. The following references report the MOT of the metal powder materials: Building Success Layer by Layer [19] and Electro Optical Systems (EOS) [20]. The MOT for the 316L powder is not available, therefore in the table it refers to the general material given by AK Steel [21]. EOS suggests using Co28Cr6Mo for components having small features such as thin walls, which require particularly high strength and/or stiffness, e.g. jet engine parts. Concept Laser suggests the application of Inconel 718 for an exhaust probe, where the gas reaches a maximum temperature of $2,150^{\circ} \mathrm{C}$. Concept Laser also suggests Co28Cr6Mo for turbine applications where components are exposed to high thermal stress of up to $1,000^{\circ} \mathrm{C}$.

The most attractive among the currently available materials in terms of MOT are Co28Cr6Mo and Inconel 718. However, for the development model of the HTR, and for the components analysed in this paper, the material selected is stainless steel grade 316L. The latter represents a good choice for developing a low-temperature functional prototype, being a cheaper material with respect to the former ones and having a sufficiently high MOT to perform relevant HTR testing and proceed for computer model validation. It should be noted that the MOT is given with particular conditions, such as mechanical stress (pressurized shells, vibration) or corrosive environment, which could underestimate the MOT in vacuum (space) environments with an inert and high purity propellant gas such as xenon. In particular, the HTR heat exchanger works at constant pressure with a small pressure drop between the inlet and the nozzle throat. On the other hand, thermal stress can be significant. For this reason, the reported MOTs are just an estimation of the maximum temperature sustainable by the low-temperature HTR prototype. 
Table 1. Maximum Operating Temperature (MOT) for commercially available SLM materials.

\begin{tabular}{lll}
\hline \multicolumn{1}{c}{ Material } & MOT, ${ }^{\circ} \mathrm{C}$ & \multicolumn{1}{c}{ Ref. } \\
\hline Cobalt Chrome Alloy Co28Cr6Mo & 1,150 & BSLL \\
Nickel Alloy Inconel 718 & 980 & BSLL \\
316L Stainless Steel & 871 & AK Steel \\
DirectSteel 20 & 800 & EOS \\
15-5PH Stainless Steel & 550 & BSLL \\
Maraging Steel 1.2709 & 400 & BSLL \\
DirectMetal 20 & 400 & EOS \\
Titanium Alloy Ti6A14V & 350 & BSLL \\
\hline
\end{tabular}

\subsubsection{Refractory metals for SLM}

Refractory metals are the candidate materials to build the HTR breadboard model, since they are electrically conductive and can achieve MOT in the region of 3,000 K. The energy density of a laser employed in SLM has been demonstrated to be high enough to melt tantalum and produce fully dense parts. The nature of the AM process with tracks, layers and large directional cooling rates provides unique solidification conditions. For tantalum this results in large columnar grains formation across layers [22]. In addition, Smit Röntgen is a manufacturer capable of controlled processing pure tungsten via the additive manufacturing technique Powder Bed Laser Melting [23]. Both collaborated with EOS GmbH to develop extensive know-how on pure tungsten SLM. The main driver of investment in this research is healthcare, in particular to build more efficient 2D CT collimators for X-ray tomography. This company currently claims the following capabilities: minimum feature size of $100 \mu \mathrm{m}$, minimum wall thickness of $100 \mu \mathrm{m}$, minimum tolerance of $25 \mu \mathrm{m}$, achievable aspect ratio of 1:700, maximum product size of $230 \mathrm{~mm} \times 230 \mathrm{~mm} \times 200 \mathrm{~mm}$. Moreover, H.C. Starck already provides a wide range of SLM powders and announced its investment in state-of-theart processing capabilities to manufacture specialised refractory metal powders, in pure and alloyed forms, for additive manufacturing [24]. In conclusion, it is clear that both commercial and academic research efforts are moving towards standardising and generally improving SLM while extending to refractory metals. The availability of these materials for SLM will eventually enable the production of the HTR breadboard model. Nevertheless, the first goal of the current research is to prove the HTR concept for SLM production.

\subsection{Production of Samples for Manufacturing Verification}

For the manufacturing verification process, more than 40 components have been produced by SLM. Table 2 summarises the AM components that are relevant to the discussion of this paper. The specimens are designed in Solidworks 2015 and exported in .STL format to be then loaded in the SLM printer Concept Laser M2 Cusing. The components are virtually disposed on the build plate, selecting appropriate orientation and adding extra support structures where necessary. There are several possible support geometries, which typically consist of a honeycombpattern regular polygon, which is extruded vertically. Once the printing process is completed, the excess powder is removed and the components are finally detached from the build plate by wire-cut EDM. The HTR heat exchangers produced have four cylinders with a nominal thickness of $500 \mu \mathrm{m}, 300 \mu \mathrm{m}, 300 \mu \mathrm{m}$ and $800 \mu \mathrm{m}$ (from the innermost). HE1 represents the first test attempt. The length of the innermost cylinder is $42 \mathrm{~mm}$, while the nozzle diverging section half-angle is $20^{\circ}$. HE2 represent the second attempt of HTR heat exchanger, where the component has been shortened. The nozzle has a throat diameter of $0.42 \mathrm{~mm}$ with $14^{\circ}$ diverging half-angle. HE2.1 to HE2.2 are two variations on the way the four concentric tubular walls are connected. They aim is to test for the best type of physical connection between the tubular elements to enable both flow recirculation and electrical continuity. HE2.1-h is equivalent to HE2.1 however printed as half-section and used for internal roughness characterisation (section 3.1.4). In all cases, residual powder is removed from the components via ultrasonic cleaning in acetone at room temperature, where each component is periodically rotated and inspected until no additional powder is observed in the cleaning solution.

$\mathrm{N} 10, \mathrm{~N} 14, \mathrm{~N} 20$ and N30 are isolated nozzles having all the same throat diameter of $0.42 \mathrm{~mm}$ and different diverging half-angles, respectively $10^{\circ}, 14^{\circ}, 20^{\circ}$ and $30^{\circ}$. The purpose was to evaluate whether the nozzle throat dimension and surface finish are dependent on the nozzle divergence half-angle, and if post-machining is necessary to meet the requirements. Finally, TW is a small component manufactured for analysis with SEM to investigate the surface morphology. 
Table 2. List of designed and manufactured AM components relevant in the discussion.

\begin{tabular}{|c|c|}
\hline ID & Description \\
\hline HE1 & First version of HTR heat exchanger \\
\hline HE2.1-h & $\begin{array}{l}\text { Second version of the HTR heat exchanger- } \\
\text { variation } 1 \text {, printed as half-section }\end{array}$ \\
\hline HE2.1 & $\begin{array}{l}\text { Second version of the HTR heat exchanger - } \\
\text { variation } 1\end{array}$ \\
\hline HE2.2 & $\begin{array}{l}\text { Second version of the HTR heat exchanger - } \\
\text { variation } 2\end{array}$ \\
\hline N10 & Isolated nozzles with different diverging half- \\
\hline N14 & angles denoted by number \\
\hline N20 & \\
\hline N30 & \\
\hline TW & Concentric thin-wall half-section \\
\hline
\end{tabular}

\subsubsection{Concept Laser M2 Cusing and Stainless Steel 316L powder}

For the purpose of the study, test specimens were manufactured with a Concept Laser M2 Cusing available at Engineering and Design Manufacturing Centre at the University of Southampton.

Table 3 shows the main features of the machine, which has a build volume $(x, y$, height $)=250 \mathrm{~mm} \times 250 \mathrm{~mm} \times 280$ $\mathrm{mm}$. The material used (CL 20ES), is a 316L (1.4404) Stainless Steel metal powder supplied by Concept Laser. Fig. 5 shows the particle size distribution while Fig. 6 shows SEM images of the powder particles. Most of the particles are spherical, but a small percentage are oval-shaped or a conglomerate of smaller particles. Fig. 7 shows the machine in operation while building some components of the current research. For relatively large components, the main body/fill of the part layer is divided into $5 \mathrm{~mm}$ squares each with a build orientation alternating 90 degrees (this pattern is visible on the left-hand components in Fig. 8). The 3D printer does not allow the build of models with a thickness below or equal to $100 \mu \mathrm{m}$. This is a technical limit set for the CONCEPT Laser M2 Cusing machine.

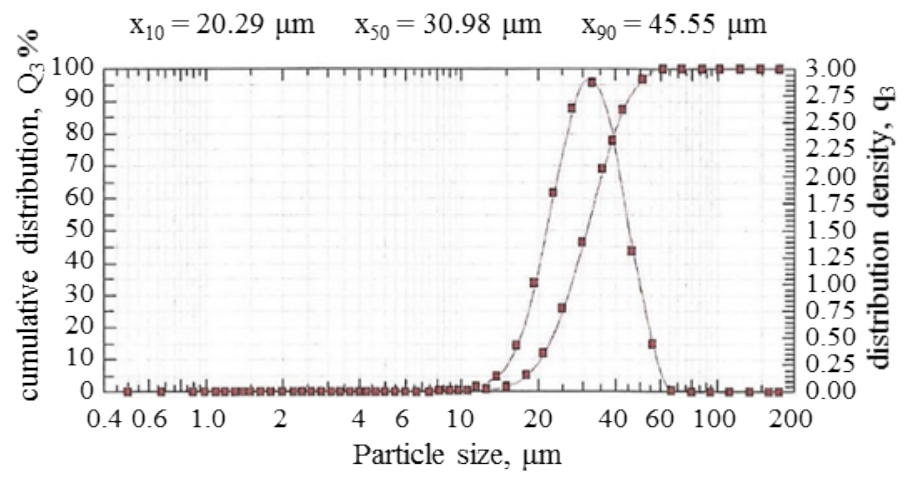

Fig. 5. 316L particle size distribution [25].

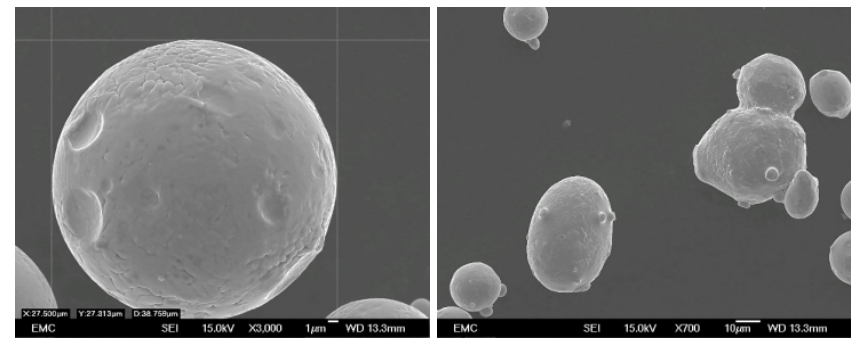

Fig. 6. Images of the Stainless Steel 316L powder taken with SEM. 


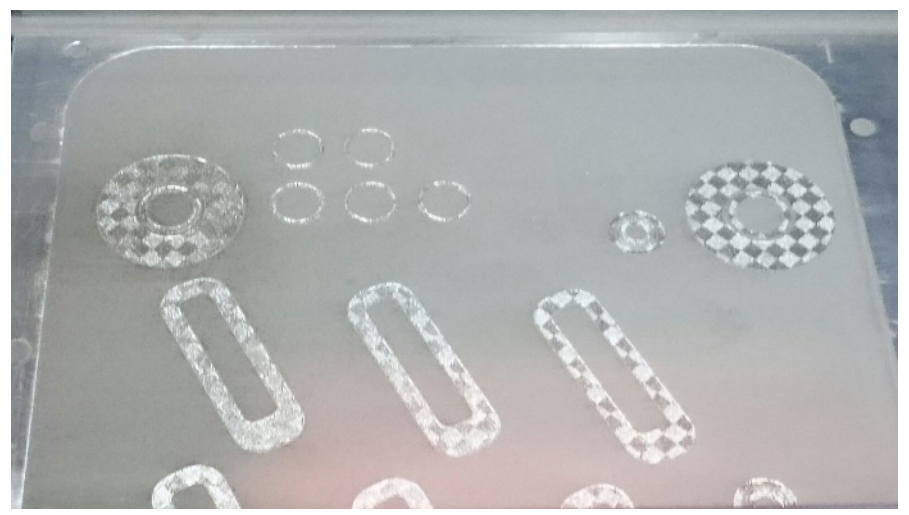

Fig. 7. Photo taken during the second printing session.

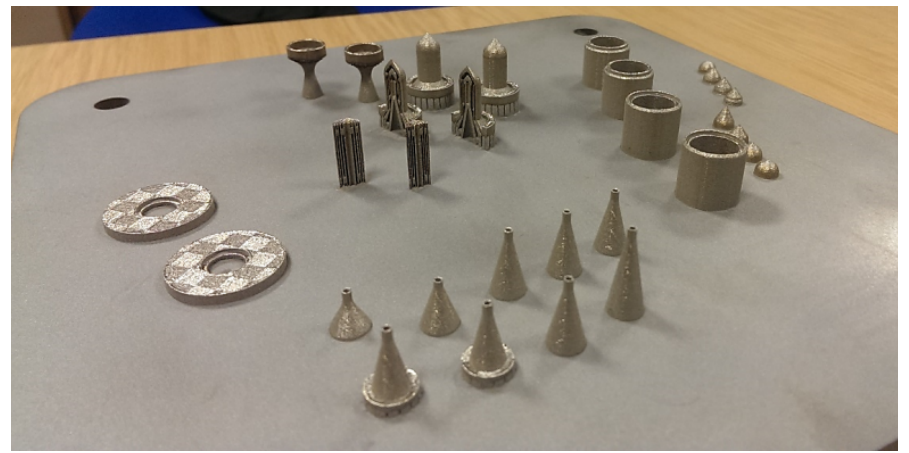

Fig. 8. A printing session overview.

Table 3. Concept Laser M2 Cusing performance data.

\begin{tabular}{lcl}
\hline \multicolumn{1}{c}{ Property } & Value & \multicolumn{1}{c}{ Comment } \\
\hline Build rate, $\mathrm{cm}^{3} \mathrm{~h}^{-1}$ & $2-20$ & Job specific \\
Laser Power, $\mathrm{W}$ & 200 & Rated \\
& 177 & Effective \\
& 132 & For support structure \\
Laser beam diameter, $\mu \mathrm{m}$ & 50 & $30 \mu \mathrm{m}$ of beam compensation \\
Layer thickness, $\mu \mathrm{m}$ & 30 & Read from screen during process \\
Scan speed, $\mathrm{ms}^{-1}$ & 0.8 & Plane \\
& 1 & Support structure \\
& 1.6 & Inside and outside contour \\
Hatch, $\mathrm{mm}$ & 7 & Max. \\
Gas & 5 & Square islands \\
\hline
\end{tabular}

\subsection{Inspection Facilities}

The optical microscope Olympus BX51, with 5 to 100 times magnification capability, is used to take measurements. Alicona-Infinite Focus is used for 3D surface profilometry, which is obtained by applying a vertical interferometer technique in order to acquire both the surface roughness and the 3D-topography characterization. Moreover, the JSM 6500 Scanning Electron Microscopy (SEM) has been used to investigate the surface morphology in detail. These optical units are located at the University of Southampton (nCATS research group). X-ray Computed Tomography is used to perform a non-destructive inspection of complex components, as well as performing nominal to actual geometry comparison to account for the displacement of the manufactured component from the actual CAD design. The $\mu$-VIS X-Ray Imaging Centre at the University of Southampton allowed for detailed CT scans on the metal components, while providing the software packages necessary to analyse them. VG Studio MAX is used to handle the full 3D dataset from which a first visual inspection can highlight possible failures in the component. A 3D surface 
mesh of the scanned component, generated with a built-in extraction tool, is finally used in GOM Inspector V8 to perform nominal to actual comparison with the CAD geometry.

\section{Results and Discussion}

\subsection{Optical inspection}

\subsubsection{Build angle results}

HE1 is the first version of the additively manufactured HTR concentric tubular design. Fig. 9 (top) shows the halfsection obtained from the whole component by wire-cut EDM. Where the nominal build angle between two conical walls was $22.76^{\circ}$, microscope measurements indicate a slight divergence of $+1.07^{\circ}$. However, taking precise measurement of the irregular wall surface is challenging. Where the design angle of the conical wall is $42.76^{\circ}$, the resulting flatness of the bottom surface (with respect to the printing direction) is particularly poor. Material conglomerates extend from the design surface as much as $400 \mu \mathrm{m}$. These protrusions represent a risk in creating short circuits between the heat exchanger walls. In general, for large build angles the melting process is supported by loose powder rather than solid material. In these cases the melted area cools quickly and eventually the stress generated twists the material, generating these irregular features in bottom surfaces [26]. Fig. 9 (a) shows same features appearing for a wider build angle of $60^{\circ}$. The wall pictured in this particular figure is a revolved circular arc forming a trumpet shape nozzle with a design thickness of $800 \mu \mathrm{m}$. The protrusion average length is similar to the previous case where manufacturing angle was approximately $40^{\circ}$. This fact suggests that these features start to form at a particular printing angle. The measured wall thickness is approximately the design value; however, there are locations where, due to the bottom surface irregularity, the local thickness reaches $660 \mu \mathrm{m}$, which is approximately the $83 \%$ of the design value. Fig. 9 (b) shows the support structure added in the manufacturing process in order to support the build of suspended parts of the component. The figure shows that these structures have a wall thickness of $100 \mu \mathrm{m}$, highlighting the ability of the printer to produce $100 \mu \mathrm{m}$ standing walls.

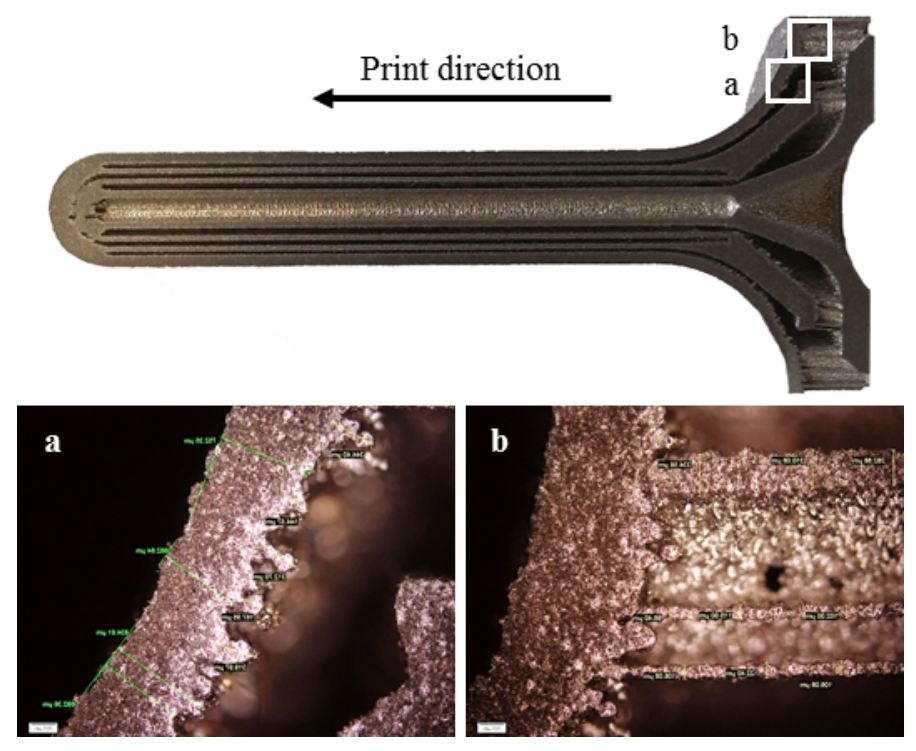

Fig. 9. HE1 section (Wild Microscope M420), the printing direction in the SLM process was from right to left.

\subsubsection{Nozzle throat results}

The objective of these nozzle tests is to determine the limits of the SLM manufacturing in terms of throat size accuracy and diverging section surface roughness. Both these parameters are a major requirement for the HTR to meet the design performance, such as thrust magnitude and vector. From this investigation, it was clear that it was not possible to produce a nozzle neither with the required throat size nor with an acceptable surface finish on the diverging expansion section. The following analysis compares four nozzles with different diverging section half-angles $\alpha$ (Fig. 10). Each nozzle has the same throat design diameter of $0.42 \mathrm{~mm}$, therefore the nominal throat area is $138,544 \mu \mathrm{m}^{2}$.

It is known that it is not possible to print a perfect small hole with its plane positioned orthogonally to the print direction. The printer is much more accurate in printing holes when in plane with the printing area. Although the 
nozzles samples have been printed vertically, the throat hole is built on a cone with a specific angle. This implies that the throat and cone diameter may be less controlled for larger $\alpha$ angles. In order to evaluate this, nozzles with different diverging angles (N10-30) have been printed to investigate on a possible correlation between the throat hole precision and this angle.Fig. 11 shows a collection of images of the investigated throats. It does appear that there is not a strong correlation between the throat contour regularity and the nozzle diverging half-angle from 10 to 30 degrees. It is clear that the nozzle area is always less than the designed one. Furthermore, the throat perimeter is irregular, which would cause flow asymmetries during operation and thus a performance loss. The throat protrusions do not seem to be directly correlated with neither the nozzle geometry nor the half-angle of the diverging section. In conclusion, as-printed nozzles do not provide the required accuracy both in terms of throat perimeter regularity and of diameter accuracy. It is therefore seen necessary to post-machine the throat in order to obtain a cylindrical hole with nominal diameter and a machine-finish of the throat area. For these reasons, the nozzle throat will be drilled to the nominal value. In addition, as-printed nozzle do not exhibit adequate surface roughness levels. Therefore, polishing of the diverging section will be required to achieve the HTR requirement of $\mathrm{R}_{\mathrm{a}}=1.6 \mu \mathrm{m}$ and $\mathrm{R}_{\mathrm{q}}=8 \mu \mathrm{m}$ or better.

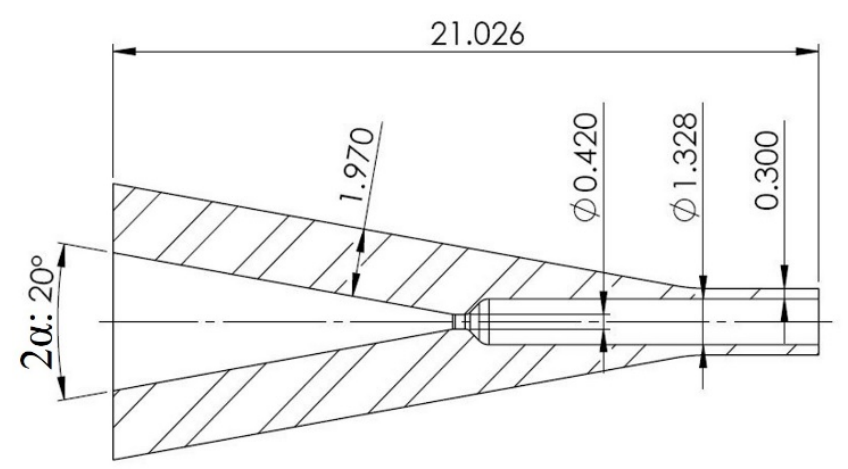

Fig. 10. Nozzle drawings of N10, dimensions in mm.

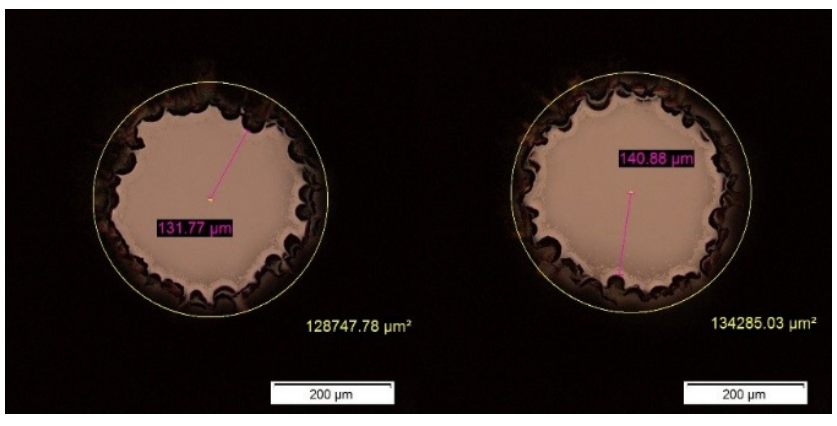

$\mathrm{N} 10\left(\alpha=10^{\circ}\right) \quad \mathrm{N} 14\left(\alpha=14^{\circ}\right)$

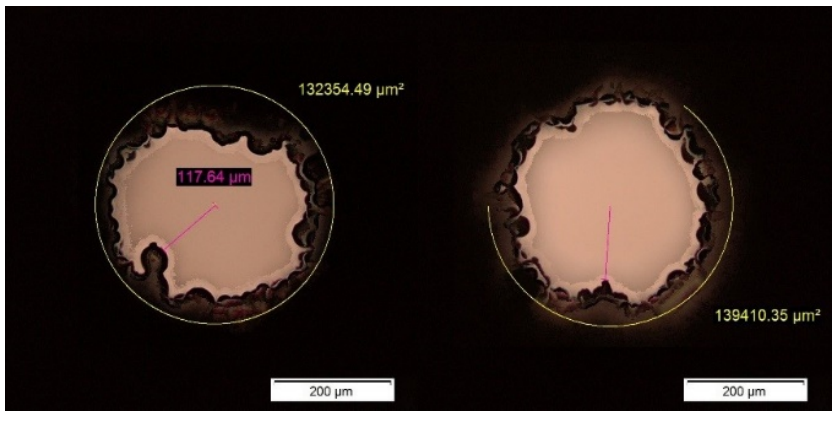

$\mathrm{N} 20\left(\alpha=20^{\circ}\right) \quad \mathrm{N} 30\left(\alpha=30^{\circ}\right)$

Fig. 11. Nozzle throat contour of as-printed nozzles. Half-angle $\alpha$ of the diverging section in parenthesis. Yellow: circle area, purple: minimal distance from centre to bigger protrusion (Olympus BX51). 


\subsubsection{Surface morphology with SEM}

In this section, the nature of the surface roughness is investigated using the SEM. Fig. 12 shows the TW test component design, highlighting the zone in which the SEM has been performed. TW consists of a section of four concentric tubular elements with a thickness of $200 \mu \mathrm{m}$. In order to achieve a smooth cross-section of the component, the sample was carefully polished down to $1 \mu \mathrm{m}$ with diamond paste. Fig. 13 shows the morphology of the area in analysis. The apparent pores on the wall section are actually the result of non-complete polishing of the section-printed component. A closer observation at the central half-cylinder shows more in detail the morphology of the vertical walls (Fig. 14). In general, the vertical walls are characterized by a relatively smooth dune-like landscape, on which powder particles are partially fused. This scenario leads to the macroscopic surface roughness of the 316L Stainless Steel SLM evaluated in section 3.1.4. The maximum measured grain powder size from datasheet is $61 \mu \mathrm{m}$, with a cumulative distribution of $99.96 \%$ (particle size distribution shown in Fig. 5). The conglomerate shown in Fig. 15 has a diameter of about $220 \mu \mathrm{m}$. This feature is one of the macro-structures composing the smooth dune-like landscape, which occasionally has also semi-spherical asperities (as in Fig. 14 bottom-right). It is also possible to see many powder particles fused to this body. The microstructure of the surface constitute the macroscopic roughness of the heat exchanger wall. For this reason, the actual wet-surface of the heat exchanger cylinders is higher than the smooth ideal cylindrical surface. This will increase the convective heat exchange between wall and propellant and will be therefore taken into account into the thruster dimensioning and modelling. If the surface roughness will represents a major problem in testing phase of the HTR, such as giving excessive pressure drop across the heat exchanger, specific chemical etching for the $316 \mathrm{~L}$ will be considered to eliminate any unfused or weakly bonded powder particles (as demonstrated in [17] for a Ti6A14V).
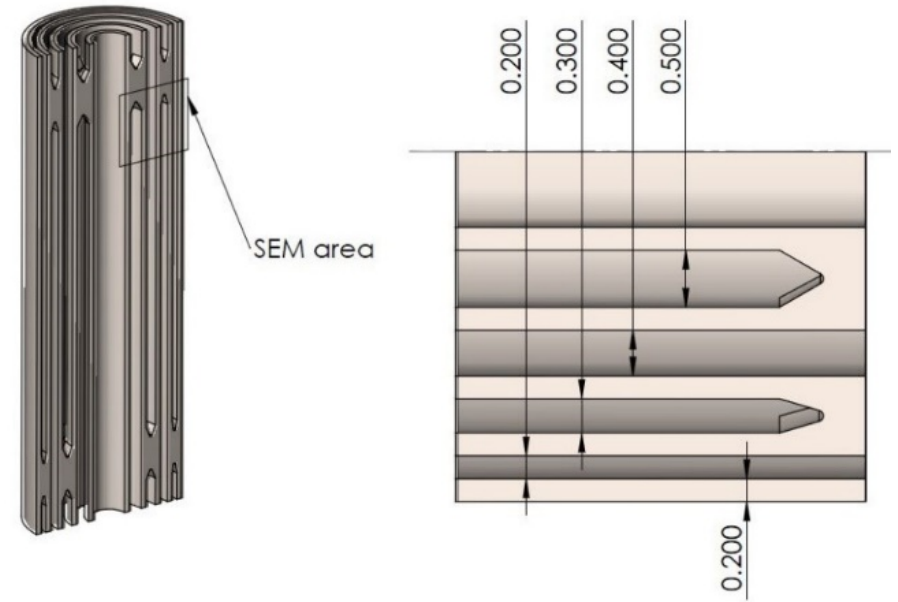

Fig. 12. TW test component design overview. The part has been printed in the vertical direction. The area of SEM analysis is highlighted (units in $\mathrm{mm}$ ). 


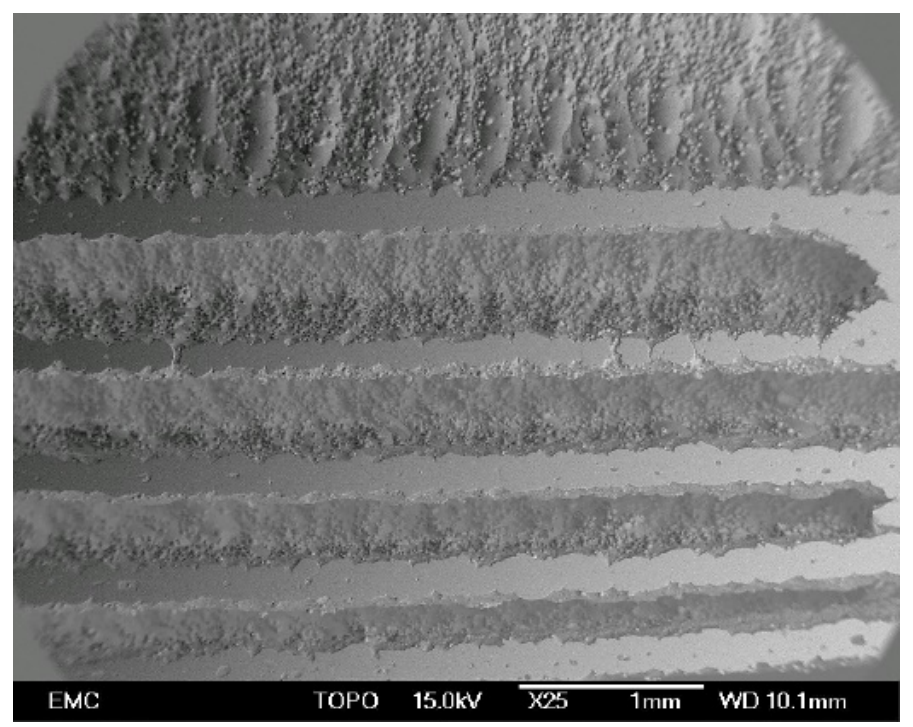

Fig. 13. TOPO-SEM of the area analysed of the component TW showing the typical surface morphology (JSM 6500 SEM).

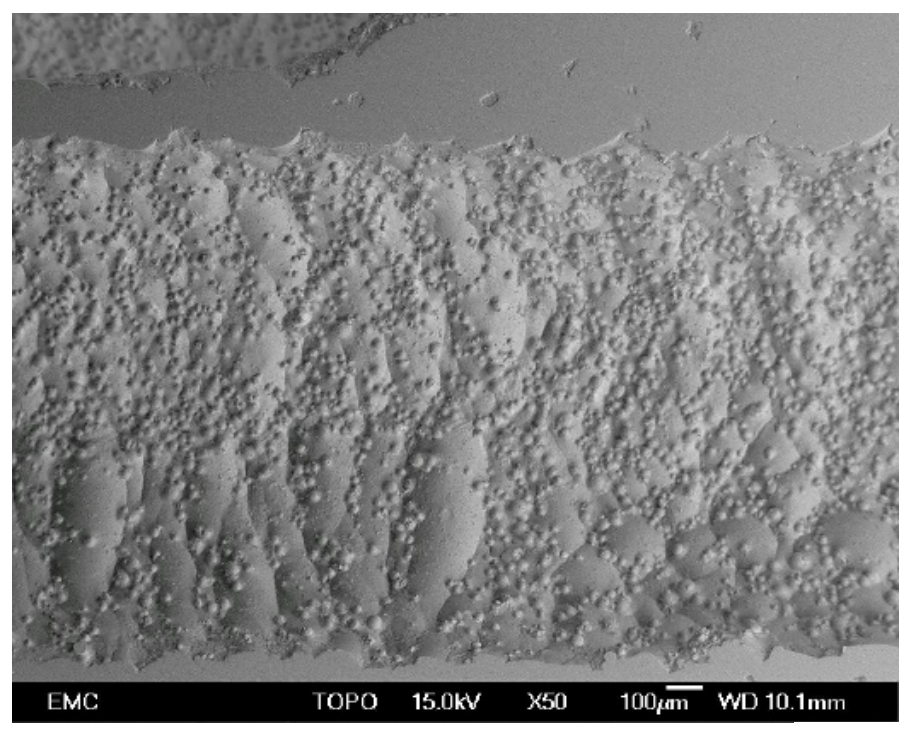

Fig. 14. Detail of the surface morphology of the inner half-tubular channel of TW (JSM 6500 SEM). 


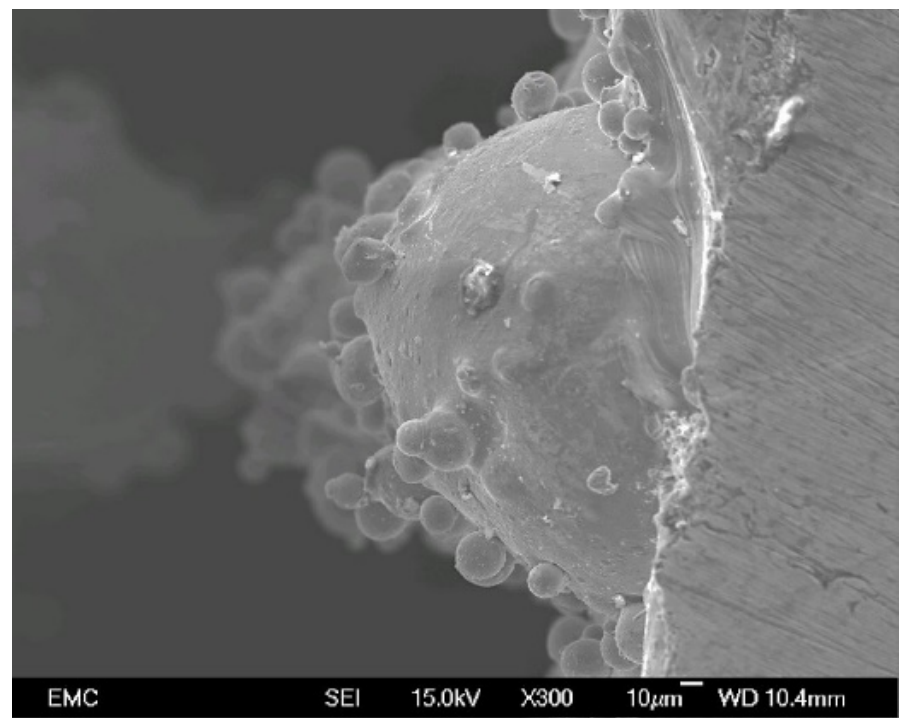

Fig. 15. Image on a wall-edge of the TW component (JSM 6500 SEM).

\subsubsection{Roughness characterisation}

It is evident that surface roughness of as-printed components may be considerably higher than expected. It is therefore necessary to evaluate its magnitude and to characterize it in different sections of the AM components, i.e. on tubular walls and the nozzle diverging wall. The section component HE2.h is subjected to a systematic surface and profile roughness analysis, while its non-sectioned geometry counterpart HE2, is subject to a nominal to actual surface comparison through X-Ray Computed Tomography inspection (section 3.2). In order to build a valuable data set, the measurements are performed three times for both the inner heat exchanger cylinder and for the nozzle regions as shown in Fig. 16 using an Alicona profilometer. Table 4 shows the spatial location of the sampled areas, with reference to Fig. 16, where the origin plane is coincident with the section surface of the component. $Z_{\text {up }}$ and $Z_{\text {down }}$ are respectively the upper and the lower values of focus for the 3D surface evaluation. The settings used for the 3D scanning are $1 \mu \mathrm{m}$ for the vertical resolution (depth), and $3 \mu \mathrm{m}$ for the lateral resolution. The average profile roughness, $\mathrm{R}_{\mathrm{a}}$, and the rootmean-square roughness, $\mathrm{R}_{\mathrm{q}}$, are determined by Eq.(5) and Eq.(6) respectively, where $\mathrm{L}$ is the path length and $\mathrm{N}$ the number of samples.

$$
\begin{aligned}
& \mathrm{R}_{\mathrm{a}}=1 / \mathrm{L} \sum_{\mathrm{n}=1}^{\mathrm{N}}\left|\mathrm{r}_{\mathrm{n}}\right| \\
& \mathrm{R}_{\mathrm{q}}=\sqrt{1 / N \sum_{n=1}^{N} r_{n}^{2}}
\end{aligned}
$$

The average height, $S_{a}$, and the root-mean-square height, $S_{\mathrm{q}}$, of the sampled area are evaluated in a similar way. Whilst the profile parameters $R_{a}$ and $R_{q}$ replicate the tactile instrument measurement on a sample path, the average parameters $\mathrm{S}_{\mathrm{a}}$ and $\mathrm{S}_{\mathrm{q}}$ are evaluated over the complete surface in the analysis.

Table 5 shows the surface texture measurement, where the waviness, or long wave component of the surface, is removed using a short wave Gaussian profile filter with a cut-off wavelength $\mathrm{L}_{\mathrm{c}}$. This is selected to be ISO conforming and therefore giving a measurement of roughness comparable to measurements done with tactile instruments. The range of values of $\mathrm{R}_{\mathrm{a}}$ corresponds a particular $\mathrm{L}_{\mathrm{c}}$ and a specific profile length necessary to provide a reliable surface roughness measurement. The surface texture measurement highlights the area ratio between the measured and the corresponding ideal form, cylindrical for the regions 1-3 and conical for the regions 4-6. This figure is higher for higher average-surface roughness $S_{a}$, to which also corresponds to a higher root-mean-square surface roughness $S_{\mathrm{q}}$. A maximum area ratio of $223 \%$ is measured in the nozzle diverging section (area 4). Furthermore, the surface roughness of inner diverging section was considered unacceptable (visibly rough). As previously discussed in section 3.1.2, typical requirement for the nozzle inner-surface finish is $\mathrm{N} 7\left(\mathrm{R}_{\mathrm{a}}=1.7 \mu \mathrm{m}, \mathrm{R}_{\mathrm{t}}=8 \mu \mathrm{m}\right)$. The measured values in the areas 4-6 (Table 6) are much higher and highlight the necessity of post-manufacturing machining to polish the surface. For this purpose, Electrode Discharge Machining (EDM), chemical etching or CNC machining can be considered. As part of the components characterization, the surface roughness represents an important parameter for both the heat 
transfer and the pressure drop analysis. Higher surface roughness of the heat exchanger walls implies a higher wet surface area. This may increase the heat transfer effectiveness within the heat exchanger in both laminar and turbulent flow regimes. On the other hand, whether the flow is turbulent the friction factor increases with the surface roughness, resulting in a larger pressure drop across the heat exchanger.

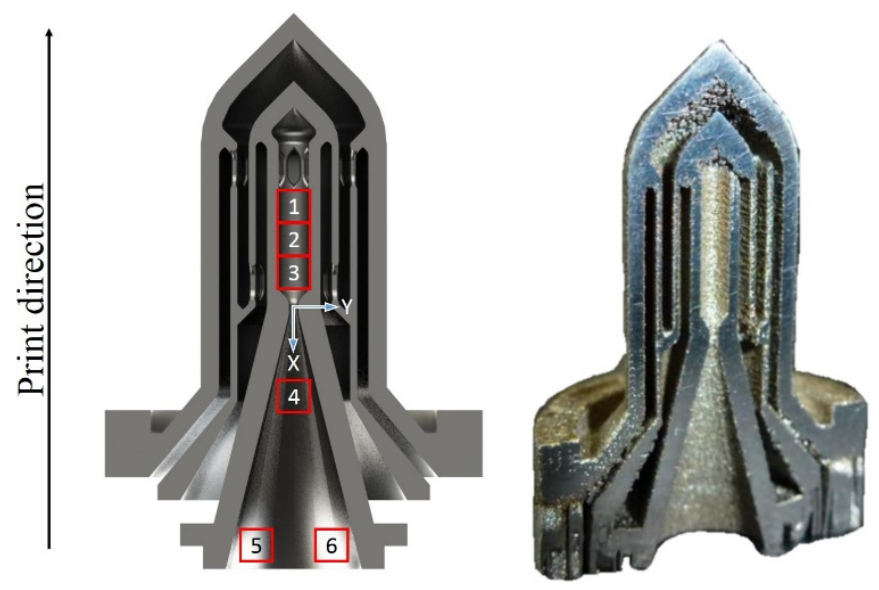

Fig. 16. HE2.1-h rendering (left) and photo (right) with highlighted areas of study for surface roughness characterization (right).

Table 4. Area location $(\mathrm{X}, \mathrm{Y})$ and $\mathrm{Z}$ direction range for the 3D image reconstruction

\begin{tabular}{ccccc}
\hline Area & $\mathrm{X}$ & $\mathrm{Y}$ & $\mathrm{Z}_{\text {up }}$ & $\mathrm{Z}_{\text {down }}$ \\
\hline & $\mathrm{mm}$ & $\mu \mathrm{m}$ & $\mu \mathrm{m}$ & $\mu \mathrm{m}$ \\
1 & -4.7624 & 103.5 & -252.4650 & -666.2300 \\
2 & -2.7585 & 32.5 & -241.0400 & -650.0900 \\
3 & -2.0035 & 46.0 & -229.6300 & -647.0300 \\
4 & 3.0975 & 13 & -289.3600 & -1043.9 \\
5 & 10.205 & -837.5 & -2130.5 & -2934.2 \\
6 & 10.245 & 658.5 & -2149.4 & -2934.2 \\
\hline
\end{tabular}

Table 5. Surface texture measurement of the 3D form-removed datasets.

\begin{tabular}{ccccc}
\hline Area & Area ratio & Projected Area, $\mathrm{mm}^{2}$ & $\mathrm{~S}_{\mathrm{a}}$ & $\mathrm{S}_{\mathrm{q}}$ \\
\hline 1 & 1.80 & 1.45 & 1.45 & 10.29 \\
2 & 1.82 & 1.5 & 1.50 & 10.63 \\
3 & 1.85 & 1.5 & 1.50 & 10.23 \\
4 & 2.23 & 1.53 & 11.71 & 15.32 \\
5 & 1.98 & 1.54 & 9.87 & 12.75 \\
6 & 2.11 & 1.53 & 10.69 & 13.64 \\
\hline
\end{tabular}

Table 6. Profile roughness measurements of the 3D form-removed dataset.

\begin{tabular}{ccccc}
\hline Area & $\mathrm{L}_{\mathrm{c}}$ & $\mathrm{ISO}$ & $\mathrm{R}_{\mathrm{a}}$ & $\mathrm{R}_{\mathrm{q}}$ \\
\hline 1 & 2500 & $4287 / 4288$ & 8.77 & 11.16 \\
2 & 2500 & 4287 & 11.83 & 16.10 \\
3 & 2500 & $4287 / 4288$ & 9.69 & 12.31 \\
4 & 8000 & $4287 / 4288$ & 18.01 & 23.01 \\
5 & 2500 & 4287 & 14.22 & 17.71 \\
6 & 2500 & 4287 & 14.81 & 18.45 \\
\hline
\end{tabular}

\subsection{Non-destructive Computed X-Ray Tomography Inspection}

Table 7 shows the main properties of the CT Scan performed on HE2.1 and HE2.2. The spatial resolution used for this scan was about $21.7 \mu \mathrm{m}$. The total number of radiograms, 587, is obtained by rotating the component about its 
centreline with an angular step of approximately $0.61^{\circ}$. These x-ray images are then assembled by post-processing software to obtain a $3 \mathrm{D}$ reconstruction of the object.

Table 7. Main properties of the Test CT Scan performed on HE2.1 and HE2.2.

\begin{tabular}{ll}
\hline \multicolumn{1}{c}{ Parameter } & \multicolumn{1}{c}{ Value } \\
\hline Image dimension & $775 \times 775 \times 1235=741,771,875$ voxels \\
Resolution of $\mathrm{x}, \mathrm{y}$ and $\mathrm{z}$ axis & $0.021703 \mathrm{~mm}$ \\
Angular Step & $0.613287^{\circ}$ \\
Total dimensions & $16.82 \times 16.82 \times 26.80=7582 \mathrm{~mm}^{3}$ \\
\hline
\end{tabular}

\subsubsection{Connection of tubular elements results}

HE2.1 and HE2.2 are two variations of the HTR heat exchanger and have the same geometry besides the interconnector design which bridges the tubular walls of the heat exchanger, ensuring continuity and forming an electrical resistance circuit. The two variants, of which the design is shown in Fig. 17 (top), have been inspected through CT to select the most appropriate one. HE2.1 has $500 \mu \mathrm{m}$ thick connectors from a wall-end to the next one with $45^{\circ}$ angle with respect to the printing direction. In HE2.2 instead, the tubular elements are fully connected, while permitting the propellant gas to flow through $500 \mu \mathrm{m}$ wide and $1.5 \mathrm{~mm}$ high fluidic channels. Fig. $17 \mathrm{shows}$ the centreline radiograms of the two components. It is clear that HE2.1 shows a major build failure (circled in red). In particular, the inner and the second outer tubular elements are shorted throughout the entire length of the device. This represents a failure for both the recirculating flow path and the electrical continuity. Repeat builds of this component have shown that the fault/failure is a consistently repeatable build failure, however the reason behind the failure is not completely clear and requires further investigation. The initial prognosis was that a primary error at the top of the intercylinder flow connectors propagated upwards layer after layer in the building process caused by poor build quality as a function of the design geometry. This additional interspatial material was not likely to be completely fused since the design should not allow the laser to melt the interspatial powder between the tubular geometries and thus may have only partially melted the material. As a result, the HE2.1 interconnector design was excluded while HE2.2 has been considered for further build investigations. The latter build presents only a minor failure of the connecting material between the nozzle and the second cylinder. Although this represents an electrical short circuit, the recirculating flow path is successfully obtained. The latter component is analysed through CT visual inspection and nominal-to-actual comparison in the following sections.

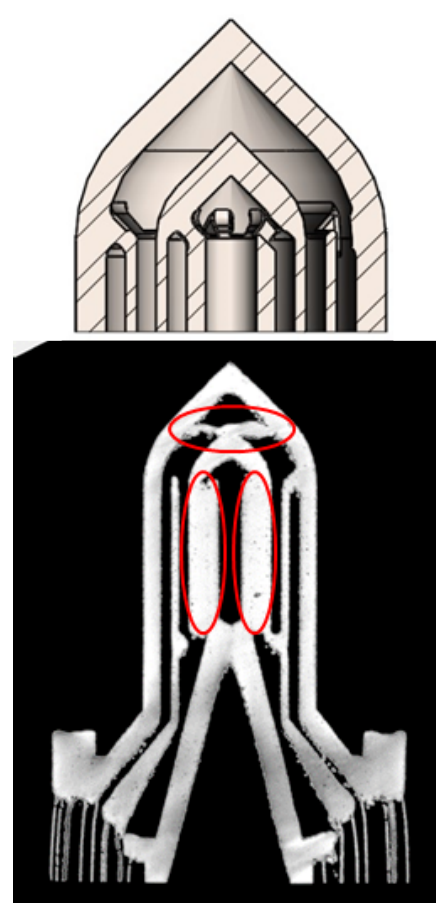

HE2.1

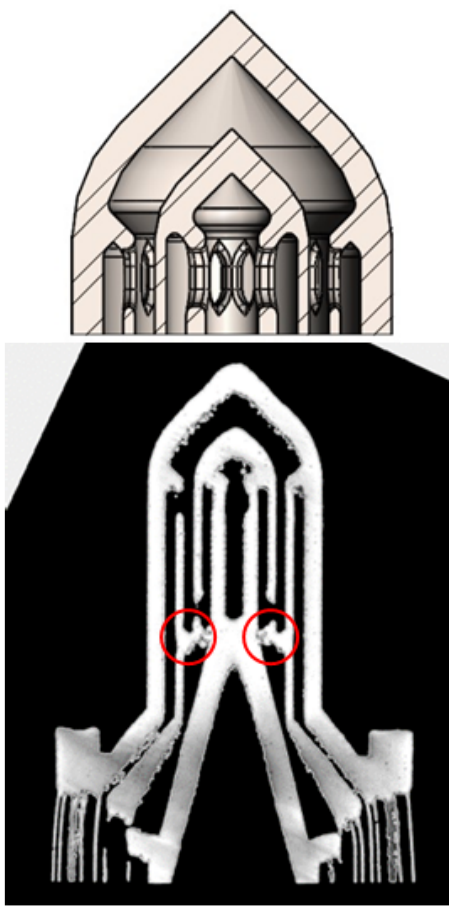

HE2.2

Fig. 17. Radiograms of central axis section (bottom) and connection design (top). Failures are circled in red.

FRomei_Acta_Astronautica_2017

Page 16 of 23 


\subsubsection{X-Ray CT Volumetric Inspection}

The minor failure of component HE2.2, observed through radiograms (section 3.2.1), can be better identified by visual inspection of the reconstructed CT volume. Fig. 18 shows the CT volume of the overall component (a), of its longitudinal section (b), and a cut-view in the nozzle region at two different planes across the component (c, d). From the visual inspection it is possible to identify a minor failure in the printing process. A short circuit is observed around the entire inner and second cylinder of the heat exchanger (circled in red). This may be due to an excessively steep build angle $\left(45^{\circ}\right)$ of the interconnection material between second and third cylinders promoting roughness. As demonstrated in section 3.1.1, steep building angles leads to the formation of very irregular bottom surfaces characterised by asperities with length on the order of $400 \mu \mathrm{m}$. These protrusion could interact and partially fuse with the inner cylinder wall eventually leading to the printing failure. The remainder of the component showed a good result of both the cylindrical elements and the fluidic channels, as demonstrated in section 3.2.3. The $45^{\circ}$ dome-shaped elbow shows a very irregular characteristic on the lower surface as expected, however this does not give rise to any functional issues for the heat exchanger.
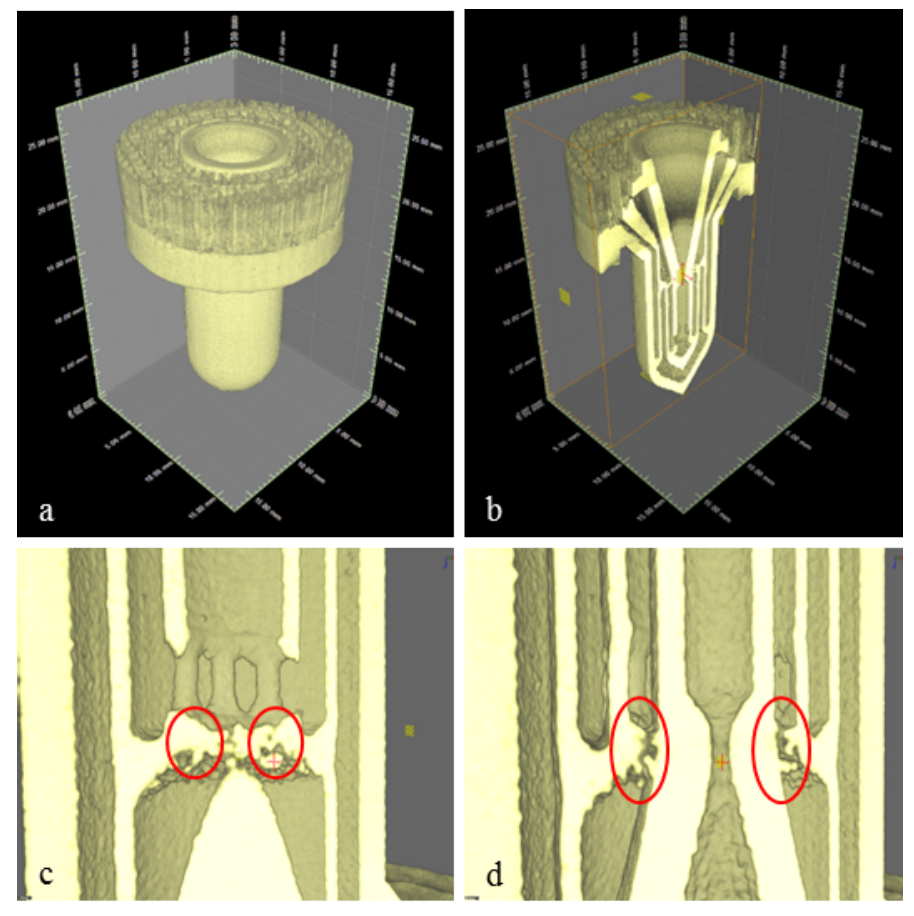

Fig. 18. Visual inspection of HE2.2 through CT volume (VG Studio MAX).

\subsubsection{Nominal-to-actual comparison}

Table 8 shows the deviation of the heat exchanger component surfaces compared to the nominal values of the design, which are overlaid using a best-fit algorithm. The best fit has been calculated using a Gaussian best-fit method with about $99.7 \%$ of all points $(3 \sigma)$, with outliers excluded from the calculation. The resulting absolute deviation shows a maximum of $49 \mu \mathrm{m}$ (cylinder 2's internal surface). Nevertheless, the deviation of the walls surfaces is always negative, showing a general trend for the manufactured cylinders diameter to be slightly smaller than the design value. The thickness and dimension accuracy is considered acceptable for this application. 
Table 8. Deviation of the actual radius of each cylinder element with respect to the nominal radius (units in mm).

\begin{tabular}{|c|c|c|c|c|}
\hline Cylinder & Nominal & Actual & Deviation & Thickness deviation \\
\hline 1 in & 0.664 & 0.648 & -0.016 & \multirow{2}{*}{+0.006} \\
\hline 1 out & 1.164 & 1.154 & -0.010 & \\
\hline 2 in & 1.664 & 1.616 & -0.049 & \multirow{2}{*}{+0.026} \\
\hline 2 out & 1.964 & 1.942 & -0.023 & \\
\hline 3 in & 2.464 & 2.418 & -0.046 & \multirow{2}{*}{+0.026} \\
\hline 3 out & 2.764 & 2.744 & -0.020 & \\
\hline 4 in & 3.264 & 3.258 & -0.006 & \multirow{2}{*}{-0.024} \\
\hline 4 out & 4.064 & 4.034 & -0.030 & \\
\hline
\end{tabular}

Fig. 19 shows an overview of the overlaid CAD design and CT derived 3D surface-mesh of the component HE2.2. In this image the connector regions are highlighted. The interflow channels of each cylinder are equally distributed radially and number between 6 and 12 for each cylinder. This feature makes the heat exchanger axially symmetric for sectors of $\pi / 3$ radians. The fluidic channel sections have been isolated for a surface comparison between the nominal geometry of the CAD model and the actual geometry of the CT scan. In general, the green colour scale shows a zerodeviation of the actual over the nominal geometry. Overall, the heat exchanger shows very good accuracy on the microfluidic channels (Fig. 20-22). Slight modifications on future HTR heat exchanger iterations will aim to limit the granular formations close to the channels, particularly for the cylinders close to the elbow recirculation region (cylinders 1 and 3). Fig. 23 and Fig. 24 show views of the section comparison in the nozzle region. As previously shown in the visual inspection (section 3.2.2), unwanted material connected cylinder 1 and 2 to creating a short circuit of the heat exchanger electrical resistance, which represents the only manufacturing failure of the component HE2.2. The presence of support material leads to a rough and irregular surface as well as geometry deformation (Fig. 25), therefore the use of support material should be avoided especially in regions where build accuracy is important. For this reason, future iterations will not include any support structure, and suspended parts of the component shall be extended with a solid construction material. Solid material can then be removed through conventional machining without distorting the base material. Finally, the throat diameter with the CT scan data can be measured in several ways. A tube obtained by a Gaussian best-fit method, gives a diameter of $0.395 \mathrm{~mm}, \sigma=0.01466 \mathrm{~mm}$ and residual of $0.01309 \mathrm{~mm}$, which is slightly smaller than the nominal value of the throat of $0.42 \mathrm{~mm}$, as measured by microscope observation (section 3.1.2).

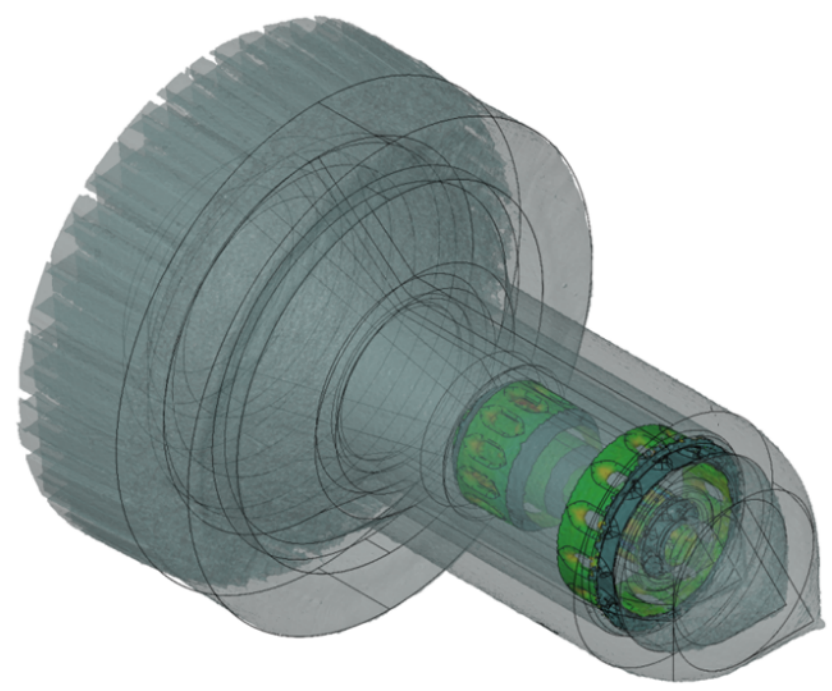

Fig. 19. HE2.2 nominal to actual comparison overview, with connecting channels highlighted (GOM Inspector V8). 


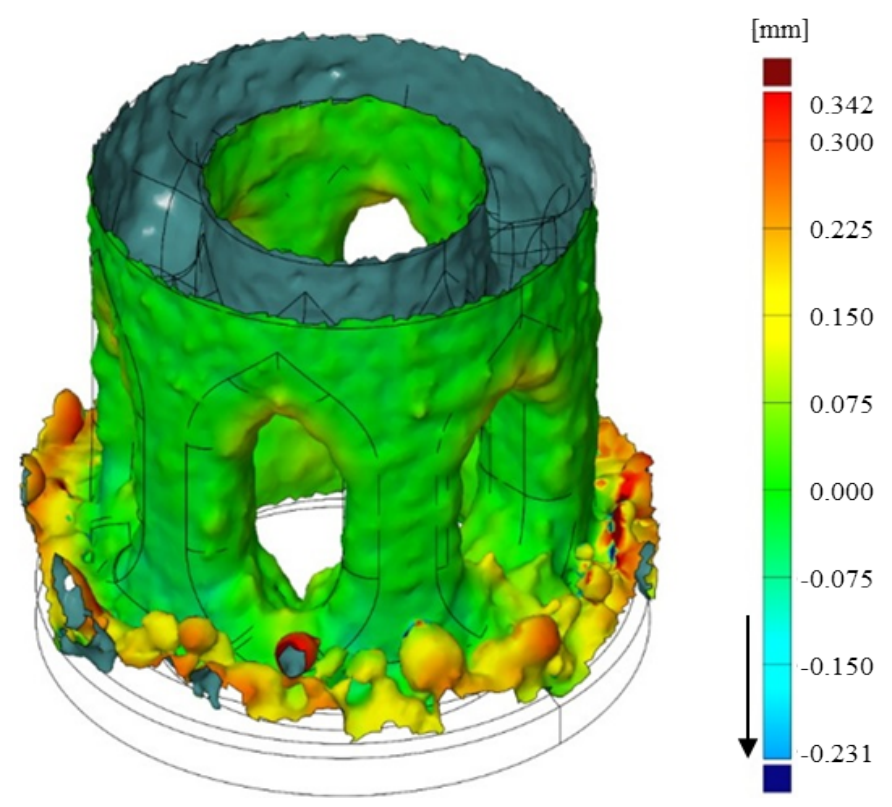

Fig. 20. Actual surface of channels located in cylinder 1.

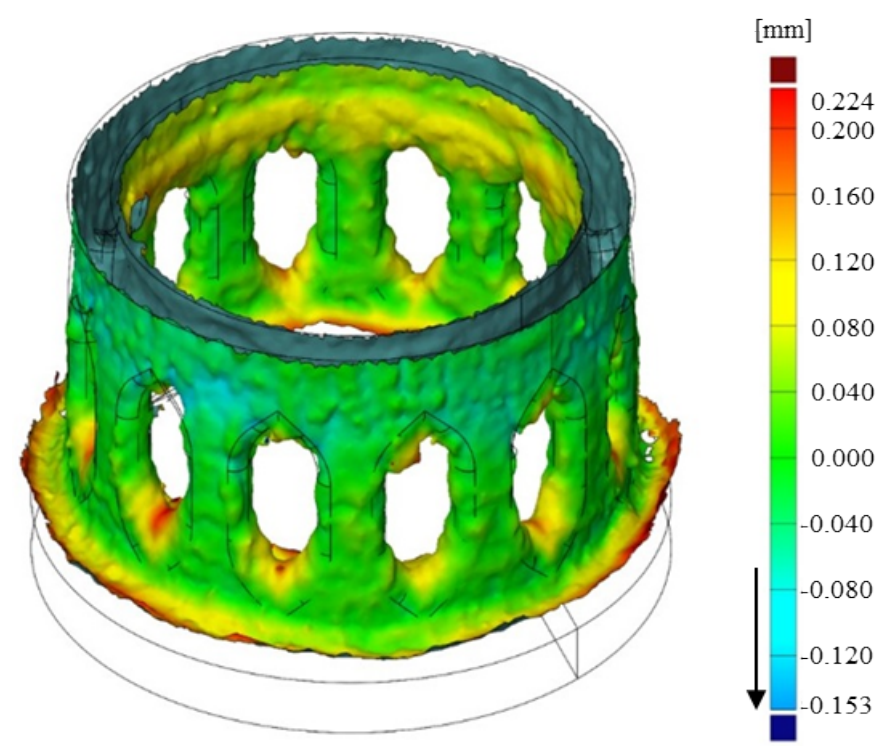

Fig. 21. Actual surface of channels located in cylinder 2. 


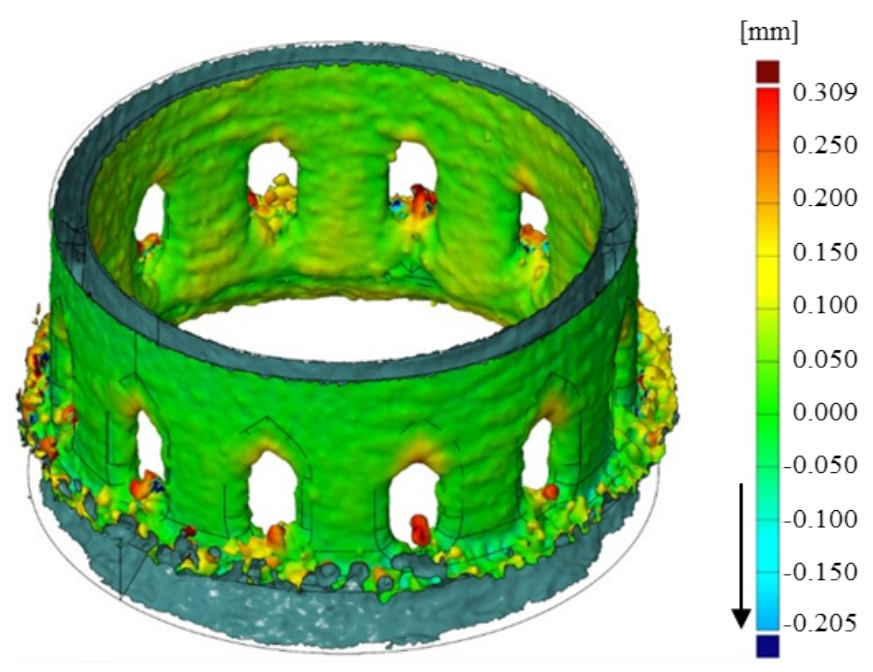

Fig. 22. Actual surface of channels located in cylinder 3.

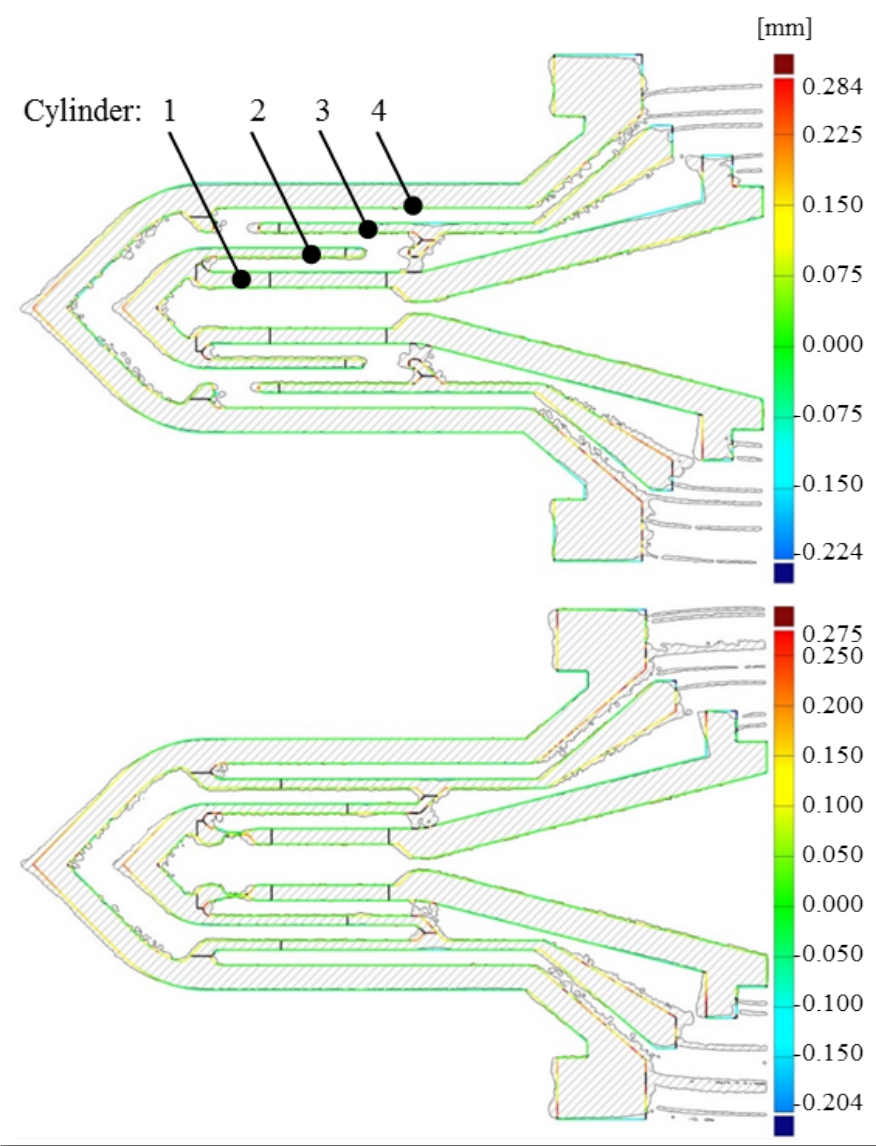

Fig. 23. Longitudinal section comparison showing the short circuit created by connecting material in the nozzle region. The two sections are orthogonal to each other, showing sections of fluidic channels for cylinder 2 and 3 (top) and for cylinder 1 (bottom) (GOM Inspector V8). 


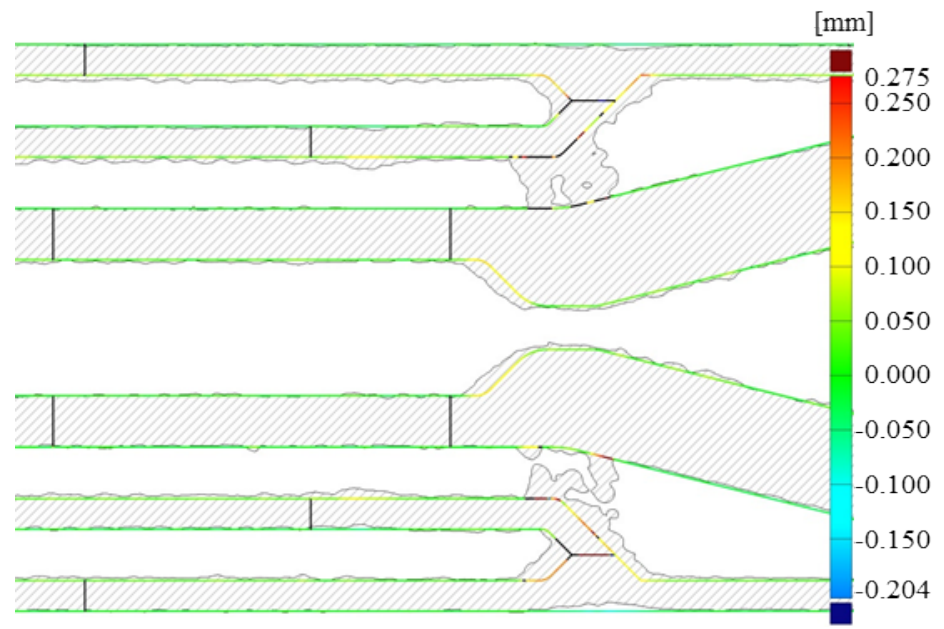

Fig. 24. Detail view of the section comparison in the nozzle region. Unwanted material connects cylinder 1 and cylinder 2 to create a short circuit of the heat exchanger electrical resistance.

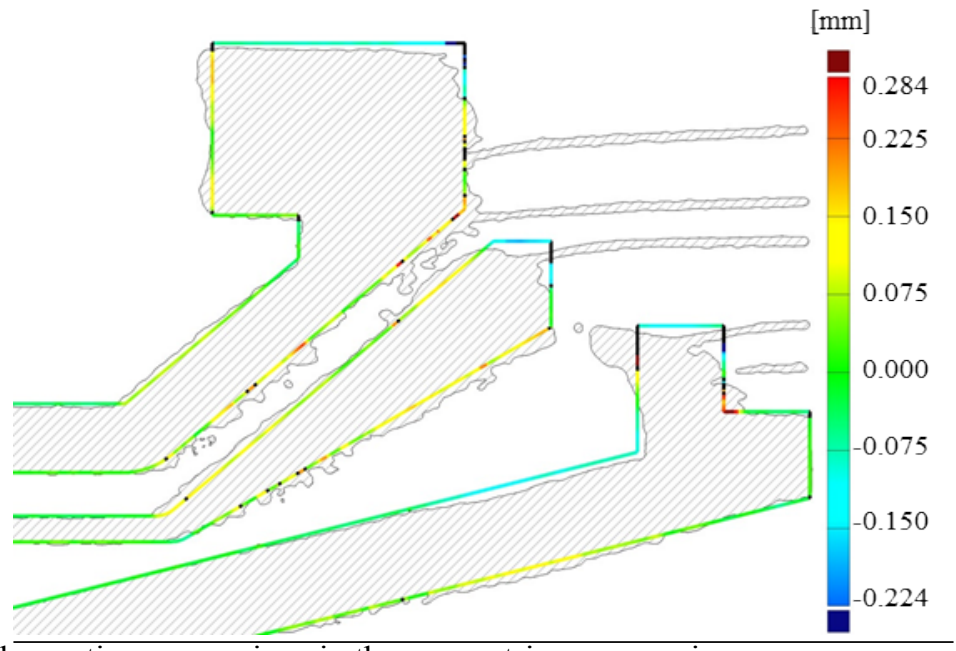

Fig. 25. Detail view of the section comparison in the concentric cones region.

\section{Conclusions and future work}

The primary objective of the current research is to enable the design, build and test a high-temperature resistojet for all-electric spacecraft manufactured through selective laser melting by verifying the manufacturing approach. A functional HTR prototype constructed from 316L stainless steel is scheduled to be built and tested within year 2017. This material verification and process validation exercise has provided the first design study to date on SLM for electric propulsion applications exploring some of the limitations of the technology, and the need for a design for manufacture approach. A methodical approach to design and characterise the SLM components has been developed which helps to understand some important aspects of design components for SLM production, such as the implications of build angle, surface roughness and small features. Manufacturing has shown to be feasible, however several design and manufacturing challenges still remain in order to completely meet the design requirements of the HTR design.

Future work will include the development and verification of post-manufacturing processes, such as the finishing of the thruster throat, polishing of the nozzle diverging section and general refining of the as-printed component, to correct some of the inadequacies of the AM process, none of which were unexpected. The study indicates that by refining the process further, there is no clear showstopper in the manufacturing of the High-Temperature Resistojet by SLM. At the time of writing, the authors are also beginning a UK Space Agency funded National Space Technology Programme project for the development of the necessary SLM parameters for sample production of refractory metal heat exchangers. It is hoped that this will lead to production of a refractory prototype within 1-year.

In conclusion, the HE1 and HE2 heat exchangers were a first attempt to build a single-piece resistive heat exchanger component to gain specific know-how of the HTR design and manufacture. Based on the lessons learned from this exercise, future iterations of the HTR heat exchanger design will allow a higher production quality and followed by 
performance testing of a prototype at the David Fearn Electric Propulsion Laboratory at the University of Southampton. A novel process of high-resolution micro Computed Tomography (CT) is applied as tool for volumetric nondestructive inspection and conformity, since the complex geometry of the thruster does not allow internal examination. The CT volume data is utilised to determine a surface mesh on which a novel perform coordinate measurement technique is applied for nominal/actual comparison and wall thickness analysis. A thin-wall concentric tubular heat exchanger design is determined to meet dimensional accuracy requirements thorough nominal/actual comparison analysis. As such the work serves to verify that the production of fine structures with feature sizes below $200 \mu \mathrm{m}$ in 316L stainless via selective laser melting is feasible and opens up new possibilities for the future developments in multiple industries.

\section{Acknowledgements}

Part of this research was funded by the Doctoral Training Partnership through the Engineering and Physical Sciences Research Council (EPSRC) [grant number EP/M50662X/1]. This work was also supported by Innovate UK in the CEOI-ST National Space Technology Programme (NSTP-2) in partnership with Surrey Satellite Technology Limited as an end-user of the technology of the High-Temperature Resistojet. The authors are also grateful for help from the $\mu$-VIS X-Ray Imaging Centre for X-ray Tomography at the University of Southampton.

\section{References}

[1] Edwards, I., A theoretical study of the performance of resistojet nozzles. 1972, University of Southampton.

[2] Nicolini, D., et al., Xenon Resistojets as Secondary Propulsion on EP Spacecrafts and Performance Result of Resistojet Using Xenon, in 28th International Electric Propulsion Conference. 2003: Toulouse, France.

[3] Coxhill, I.G. and D. Gibbon, A Xenon Resistojet Propulsion System for Microsatellites, in 41st AIAA/ASME/SAE/ASEE Joint Propulsion Conference \& Exhibit. 2005: 10-13 July.

[4] Grubisic, A.N., Microthrusters based on the T5 and T6 hollow cathodes. 2011, University of Southampton.

[5] Coletti, M., et al., Solar Electric Propulsion Subsystem Architecture for an All Electric Spacecraft. 2011, InTech. p. 123-138.

[6] Gibbon, D., I. Coxhill, and M. Drube, The Design, Build Test and In-Orbit Performance of the Giove-A Propulsion System, in 5th International Spacecraft Propulsion Conference. 2008: Crete.

[7] Delft, T., Resistojet Web Page. http://www.lr.tudelft.nl/, 2017.

[8] Halbach, C.R., R.J. Page, and R.A. Short, 3-KW Concentric Tubular Resistojet Performance. Journal of Spacecraft and Rockets, 1966. 3(11): p. 1669-1674.

[9] Page, R.J. and R.A. Short, Ten-Millipound Resistojet Performance. J. SPACECRAFT, 1968. 5(7): p. 857858.

[10] Sherwood, P., Construction of a High Performance Resistojet for Satellite Propulsion. 1978, DTIC Document.

[11] Frazier, W.E., Metal Additive Manufacturing: A Review. Journal of Materials Engineering and Performance, 2014. 23(6): p. 1917-1928.

[12] Yasa, E. and J. Kruth, Application of Laser Re-Melting on Selective Laser Melting Parts. Advances in Production Engineering \& Management, 2011. 6(4): p. 259-270.

[13] Abele, E., et al., Selective laser melting for manufacturing of thin-walled porous elements. Journal of Materials Processing Technology, 2015. 215: p. 114-122.

[14] Calignano, F., et al., Influence of process parameters on surface roughness of aluminum parts produced by DMLS. The International Journal of Advanced Manufacturing Technology, 2013. 67(9-12): p. 2743-2751.

[15] Löber, L., et al., Comparison of different post processing technologies for SLM generated $316 \mathrm{l}$ steel parts. Rapid Prototyping Journal, 2013. 19(3): p. 173-179.

[16] Cherry, J., et al., Investigation into the effect of process parameters on microstructural and physical properties of $316 \mathrm{~L}$ stainless steel parts by selective laser melting. The International Journal of Advanced Manufacturing Technology, 2015. 76(5-8): p. 869-879.

[17] Kruth, J.-P., et al., Additive manufacturing of metals via Selective Laser Melting: Process aspects and material developments. 2015.

[18] Romei, F., et al., A Thermo-Fluidic Model for a Low Power Xenon Resistojet, in International Electric Propulsion Conference. 2015: Hyogo-Kobe, Japan.

[19] BSLL. Building Success Layer by Layer. 2016; Available from: http://www.3trpd.co.uk/.

[20] EOS. EOS GmbH Electro Optical System. 2016; Available from: http://www.eos.info/en.

[21] AKSteel, Datasheet: 316/316L Stainless Steel. 2016.

FRomei_Acta_Astronautica_2017

Page 22 of 23 
[22] Thijs, L., et al., Strong morphological and crystallographic texture and resulting yield strength anisotropy in selective laser melted tantalum. Acta Materialia, 2013. 61(12): p. 4657-4668.

[23] SmithRontgen. Smit Rontgen. 2016; Available from: http://www.smitroentgen.com/.

[24] H.C. Starck Invests in Powder Processing Technology for Additive Manufacturing. 2016, H.C. Starck press office.

[25] ConceptLaser, Datasheet: metal powder CL 20ES. 2016.

[26] EPMA, Introduction to Additive Manufacturing Technology - a guide for designer and engineers. 2012.

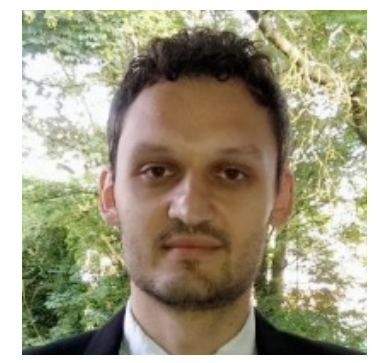

Federico Romei received both B.Sc. and M.Sc. degrees in aerospace engineering from University of Bologna, Italy. He is currently pursuing the Ph.D. degree in electric propulsion with the University of Southampton, UK, with focus on development of hightemperature resistojet for all-electric spacecraft. His Ph.D. research is sponsored by the Engineering and Physical Sciences Research Council (EPSRC).

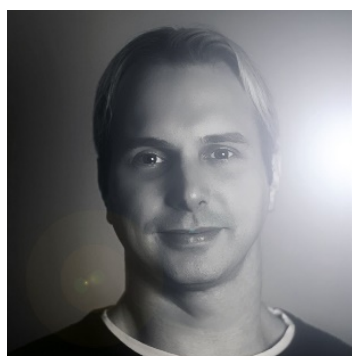

Angelo Grubišić was born in Walsall, England in 1981. He received his $\mathrm{PhD}$ from the University of Southampton and MSc from the International Space University in 2009 and 2005 respectively. He has worked extensively on the development of gridded ion thrusters, including the NSTAR ion thruster at NASA JPL and the T6 ion thruster as a consultant for QinetiQ. From 2010 to 2013, he was responsible for implementing the systems level qualification test for the T6 Bepi Colombo Mission Solar Electric Propulsion System, the highest power dual ion thruster system to date. Since then, he has been developing selective laser melting additive manufacturing technologies for production of advanced propulsion systems as a Lecturer of Astronautics at the University of Southampton.

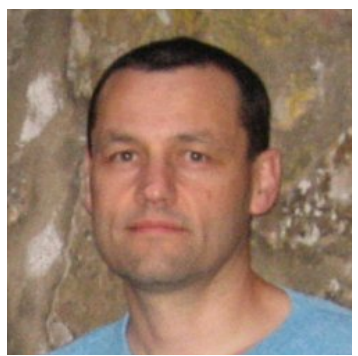

Dave Gibbon is currently the technical lead for propulsion systems at Surrey Satellite Technology Ltd. He graduated with a degree in Mechanical Engineering from Manchester University. He has over 32 years experience building propulsion systems. Initially he was responsible for the provision of bipropellant and monopropellant chemical propulsion systems for geostationary spacecraft. At SSTL he has been responsible for the design, build test and operations of all SSTL propulsion systems. $\mathrm{He}$ designed the resistojet thrusters flown by SSTL on 26 spacecraft to date with butane, xenon and water as propellants. He is a Fellow of the Institution of Mechanical Engineers. 